\title{
Report to the American Physical Society by the study group on physics problems relating to energy technologies: Radiation effects on materials*
}

APS Study Group Participants

F. L. Vook, Chairman

Sandia Laboratories, Albuquerque, New Mexico 87115

H. K. Birnbaum

University of Illinois, Urbana, Illinois 61801

T. H. Blewitt

Argonne National Laboratory, Argonne, Illinois 61439

W. L. Brown

Bell Telephone Laboraries, Murray Hill, New Jersey 07974

J. W. Corbett

State University of New York at Albany, Albany, New York 12135

J. H. Crawford, Jr.

University of North Carolina, Chapel Hill, North Carolina 27514

A. N. Goland

Brookhaven National Laboratory, Upton, New York 11973

G. L. Kulcinski

University of Wisconsin, Madison, Wisconsin 53706

M. T. Robinson

Oak Ridge National Laboratory, Oak Ridge, Tennessee 37830

D. N. Seidman

Cornell University, Ithaca, New York 14850

F. W. Young, Jr.

Oak Ridge National Laboratory, Oak Ridge, Tennessee 37830

\section{APS Council Review Committee}

\section{J. Bardeen}

University of Illinois, Urbana, Illinois 61801

R. W. Balluffi

Cornell University, Ithaca, New York 14850

J. S. Koehler

University of Illinois, Urbana, Illinois 61801

G.H. Vineyard

Brookhaven National Laboratory, Upton, New York 11973

(Received 10 July 1975)

\begin{abstract}
An APS sponsored study reviewed the state of research and development in radiation effects on materials for the purpose of identifying basic scientific problems which limit progress in energy applications and which could be attacked by physicists, especially those in universities. The field of radiation effects on materials has particular application throughout fission and fusion reactor technology, and the technological problems associated with these reactors were reviewed. Important scientific problem areas discussed included mechanical properties, point defects, voids and dislocations, theory of damage production, charged particle simulation of neutron damage, hydrogen and helium in materials, interaction of surfaces and radiation, insulators, semiconductors, and superconductivity. Although limited progress has been made on many of the scientific problems previously identified, the current energy crisis has greatly increased the economic urgency of improved understanding. In addition to many detailed suggestions, the study recommended increased effort on the following most important problem areas: $A$ firm experimental and theoretical base for ion and electron simulation of neutron damage should be established. Increased emphasis should be placed on understanding the effects of impurities on the production, migration, and agglomeration of radiation produced defects, particularly the nucleation and growth of voids and dislocation loops. The experimental and theoretical understanding of mechanical properties as they are affected by point defects and their agglomerates, impurities, and defect-impurity combinations should be established. Experimental and theoretical understanding should be established for the dynamic effects of high flux irradiations such as enhanced diffusion, creep, precipitation, and re-solution. To aid the application of basic science to technology, increased university and laboratory cooperation was recommended.
\end{abstract}

*This work was supported by the United States Energy Research and Development Administration, ERDA. 
Rev. Mod. Phys., Vol. 47, Suppl. No. 3, Winter 1975 


\section{CONTENTS}

I. Introduction and Recommendations ........... S4

A. Introduction $\mathrm{S4}$

B. Recommendations $\mathrm{S5}$

1. General recommendations S5

2. Specific recommendations S5

II. Technological Problems............... S8

A. Controlled thermonuclear reactors

1. Introduction

2. Operating environment

3. Mechanical property

4. Dimensional stability

5. Required information

B. Thermal reactors

C. Fast-breeder reactors

III. Point Defects in Metals . . . . . . . . . . . . S14

A. Introduction S14

B. Present status of knowledge $\quad$ S14

C. Basic areas of uncertainty S14

D. Promising areas of research $\quad$ S15

IV. Voids and Dislocations in Metals ........... S16
A. Introduction
S16
B. Nucleation problems
S16
C. Growth problems
D. Point defect-impurity atom interactions
S17
E. Saturation mechanisms
F. Specific recommendations
S18
S18

V. Theory of Damage Production............ S20

VI. Simulation of Reactor Neutron Damage......... S22

A. Introduction

$\mathrm{S} 22$
B. Status of technology $\quad$ S23

1. Charged particle simulation $\mathbf{S 2 3}$

2. Simulation with neutron sources $\quad \mathrm{S} 24$

C. Recommendations $\quad \mathrm{S} 25$

VII. Hydrogen and Helium in Metals............. S26

A. Hydrogen in metals $\quad \mathrm{S} 26$

B. Helium in metals $\quad \mathbf{S 2 7}$

$\begin{array}{ll}\text { C. Specific recommendations } & \text { S28 }\end{array}$

VIII. Interaction of Surfaces and Radiation. . . . . . . S29

$\begin{array}{ll}\text { A. The problems } & \mathrm{S} 29\end{array}$

B. Recommendations $\quad \mathbf{S 3 0}$

IX. Insulators $\ldots \ldots \ldots \ldots \ldots \ldots \ldots \ldots \ldots \ldots \ldots \ldots \ldots \ldots$

A. Introduction $\quad \mathrm{S31}$

B. Discussion of specific problem areas $\quad \mathrm{S} 32$

1. Reactor materials $\quad \mathrm{S} 32$

2. Ancillary opportunities S33

C. Research priorities $\quad$ S33

1. Reactor materials $\mathrm{S33}$

2. Crystal growth $\quad \mathrm{S33}$

$\mathrm{x}$. Semiconductors $\ldots \ldots \ldots \ldots \ldots \ldots \ldots \ldots \ldots \ldots$

XI. Superconductivity $\ldots \ldots \ldots \ldots \ldots \ldots \ldots \ldots \ldots$ S36
A. Introduction $\quad \mathrm{S36}$
B. Present status of knowledge $\quad$ S36
C. Basic unknowns $\quad \mathrm{S36}$
D. Promising areas of research $\quad \mathrm{S36}$

XII. Interactions Between Universities and

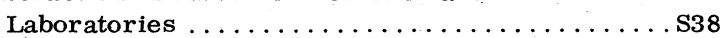

Acknowledgement . . . . . . . . . . . . . . . S39

References.......................... 440 


\section{LIST OF ABBREVIATIONS USED IN THE TEXT}

$\begin{array}{lll}\text { AEC } & \text { United States Atomic Energy Commission } & \text { ERDA } \\ \text { AERE } & \text { United Kingdom Atomic Energy Research } & \\ & \text { Establishment } & \text { ESR } \\ \text { APS } & \text { American Physical Society } & \text { fcc } \\ \text { appm } & \text { atomic parts per million } & \text { FIM } \\ \text { APW } & \text { augmented plane wave } & \text { HVEM } \\ \text { ASM } & \text { American Society for Metals } & \\ \text { ASTM } & \text { American Society for Testing and Materials } & \text { IAEA } \\ \text { bcc } & \text { body centered cubic } & \text { KFA } \\ \text { BNES } & \text { British Nuclear Energy Society } & \text { LAMPF } \\ \text { CTR } & \text { Controlled Thermonuclear Reactor } & \text { LASL } \\ & \text { Controlled Thermonuclear Research } & \text { LCTR } \\ (d, n)(n, \alpha) & \text { represent nuclear reactions; the first } & \text { LMFBR } \\ (n, d)(n, p)(n, \gamma) & \text { letter represents high energy incident par - } & \\ & \text { ticle, the second the emitted particle } & \text { MOS } \\ & d \text {-deuteron } & \text { ORMAK } \\ & n-\text { neutron } & \text { PKA } \\ & \alpha-\text { alpha particle } & \text { RTPR } \\ & p \text {-proton } & \text { SAP } \\ \text { dpa } & \gamma \text { SCF- } X-\alpha \\ \text { D-T } & \text { displacements per atom } & \\ \text { EBR2 } & \text { deuterium-tritium fusion reaction } & \text { SIA } \\ & \text { Experimental Breeder Reactor 2 } & \text { UWMAK-1 }\end{array}$

\author{
United States Energy Research and \\ Development Administration \\ electron spin resonance \\ face centered cubic \\ field ion microscope \\ high voltage electron microscopy \\ high voltage electron microscope \\ International Atomic Energy Agency \\ Kernforschungsanlage \\ Los Alamos Meson Physics Facility \\ Los Alamos Scientific Laboratory \\ Laser Controlled Thermonuclear Reactor \\ Liquid-Metal Fast Breeder Reactor \\ Reactor \\ metal-oxide-semiconductor \\ Oak Ridge tokamak \\ primary knock-on-atom \\ Reference Theta Pinch Reactor \\ sintered aluminum product \\ Self-consistent field with variable Slater \\ exchange \\ self-interstitial atom \\ University of Wisconsin tokamak
}

\section{INTRODUCTION AND RECOMMENDATIONS}

\section{A. Introduction}

This report presents the conclusions and recommendations of a summer study on Radiation Effects on Materials, which was sponsored by the American Physical Society as one of a series on Physics Problems Relating to Energy Technologies. The goal of the summer study was to survey the state of research and development in radiation effects on materials for the purpose of identifying basic scientific problems which limit progress in energy applications and which could be investigated by physical scientists, especially those in universities.

The United States is conducting an intensive search for more and lower cost energy. Because of its relatively low cost, nuclear energy is rapidly becoming an important source of such energy. In $19746 \%$ of the electricity generated in this country was provided by nuclear reactors, up from 3\% in 1973 and $1 \%$ in 1972. At present in some areas such as New England and Chicago, more than $1 / 4$ of the electric power is provided by nuclear reactors. The recently increased costs for fossil fuels have made the operating costs of nuclear power plants significantly lower than the pres- ent alternatives. ${ }^{1}$ However, there are still unsolved technological problems in the present and projected nuclear industry. Many of these problems arise from the interaction of nuclear particles with the solid materials in the reactor.

The radiation effects research done in the past has been of great value in the design of the power reactors now in operation. However, it is important to realize that a considerably enhanced effort in radiation effects research will be required to provide the insight and information necessary for the solution of problems in the present light-water reactors and especially for the design of future fission and fusion reactors which will

\footnotetext{
${ }^{1}$ Power generated by nuclear power plants now planned for completion in 1983 by the New England Electric System is estimated to cost $\$ 0.024$ per kilowatt hour versus $\$ 0.038$ and $\$ 0.034$, respectively if plants were built for oil or coal. Primarily because of increased construction costs, this nuclear power cost is still more than double the estimated $\$ 0.01$ per kilowatt hour long term cost of power from New England nuclear plants built in the late 1960s and early 1970s. Wall Street Journal, June 21, 1974.
} 
operate at temperatures and particle fluxes far exceeding those of present-day reactors.

In 1972 the AEC Division of Phy sical Research sponsored two very useful meetings, mostly limited to AEC contractors, on "Fusion Reactor First Wall Materials" (AEC/ WASH $-1206,1972$ ) and on "Critical Questions in Fundamental Radiation Effects Research" (AEC/WASH $1240,1973)$. As we will delineate in the present report many of the scientific problems identified in the previous AEC reports have shown limited progress, but the economic urgency of increased understanding is greater than ever.

We note that although the scientific and technological research areas which warrant increased effort by the scientific community have existed unabated, recent years have seen a decline in funding, a decline in the number of graduate students, and indeed layoffs in government laboratories working in the materials science area. Only recently has funding increased for this kind of research. We wish to emphasize that an increased and stable funding policy is necessary.

Advances to ease the energy crisis will be limited by technical insight and the availability of competent scientific manpower as well as by the availability of funds. An important source of such manpower can be found at universities. More cooperation between university physicists and those at industrial and government laboratories is strongly recommended. There are many problems on which the research can be performed at universities. This can be of significant help in the proper training of graduate students and will also keep the research faculty aware of current developments. In the past, work on industrial problems used to be common in university physics departments as well as the temporary employment of graduate students and faculty at industrial laboratories. All sides benefit from these cooperative efforts and the interaction of scientific talents. Such arrangements also remove, to a great extent, the manpower limitations.

The field of radiation effects studies has applications throughout fission and fusion reactor technology as well as in space technology. Deficiencies in understanding the changes induced by radiation in materials used in reactors have led to costly modifications in design and operational procedures. Such induced effects are the embrittlement of materials and their swelling by the formation of voids inside them. Lack of complete knowledge of these complex processes in engineering materials requires periodic retrieval of samples from present light-water reactors for material testing; in some cases it requires operation at lower power than the design intended, and the need for more auxiliary equipment. There is also the possibility that the deterioration of the containing vessel may make it necessary to shut down the reactor and thus shorten its useful life. Z. Zebroski of the Electric Power Research Institute has estimated the direct and indirect economic impacts of these deficiencies in knowledge at about $\$ 480$ million in 1974 , increasing to over $\$ 1$ billion in 1982 , as shown in Table I (Zebrowski 1974).

The effects mentioned here will be especially crucial in future breeder and fusion reactors, for which the neutron flux will be very high. For example, the swelling effect could slow down the breeding of new fuel in a breeder reactor and make it uneconomical.

Radiation effects problems in materials other than reactor materials were also considered in this study but to a much lesser degree. In space environments, the effects of Van Allen and solar wind irradiations on semiconductor materials and devices such as solar cells have received extensive investigation. Of particular interest at the present time are studies of the effects of radiation on the insulating oxides and nitrides of metal-oxide-semiconductor (MOS) devices. These devices are important because of their small size and very low power consumption.

For these reasons we urge more effort designed to obtain fundamental understanding of the basic physics of radiation effects on materials. This better understanding will often lead to technological solutions to the problems or at least delineate the limits of the solutions. More work is also necessary to relate the results of the basic research to the technological applications. It should be recognized, however, that research requires long lead times to be incorporated into technological practice.

In the following sections of this report we first discuss the more important technological problems resulting from the effects of radiation on materials; then we subdivide the subject into several areas of research and in each section we indicate the present status, the basic unknowns and areas of uncertainty, and promising areas of research.

\section{B. Recommendations}

\section{General recommendations}

We make the following general recommendations for increased effort to attack the most important scientific problem areas that limit progress in energy applications involving radiation effects on materials:

- A much firmer experimental and theoretical base for ion and electron simulation of fission and fusion neutron damage should be established.

- Increased emphasis should be placed on understanding the effects of impurities on the production, migration, and agglomeration of radiation-produced defects, particularly the nucleation and growth of voids and dislocation loops.

- The experimental and theoretical understanding of mechanical properties as they are affected by point defects and their agglomerates, impurities, and defectimpurity combinations should be significantly improved.

- Experimental and theoretical understanding should be established for the dynamic effects of high flux irradiations such as enhanced diffusion, creep, precipitation and re-solution.

\section{Specific recommendations}

More detailed specific recommendations of this study are contained in each of the respective sections of this report and are summarized below. The most urgent recommendations are marked with a $\bullet$. 
TABLE I. Economic impacts to the nuclear power industry of deficiency in understanding of radiation effects on materials. $a, b$

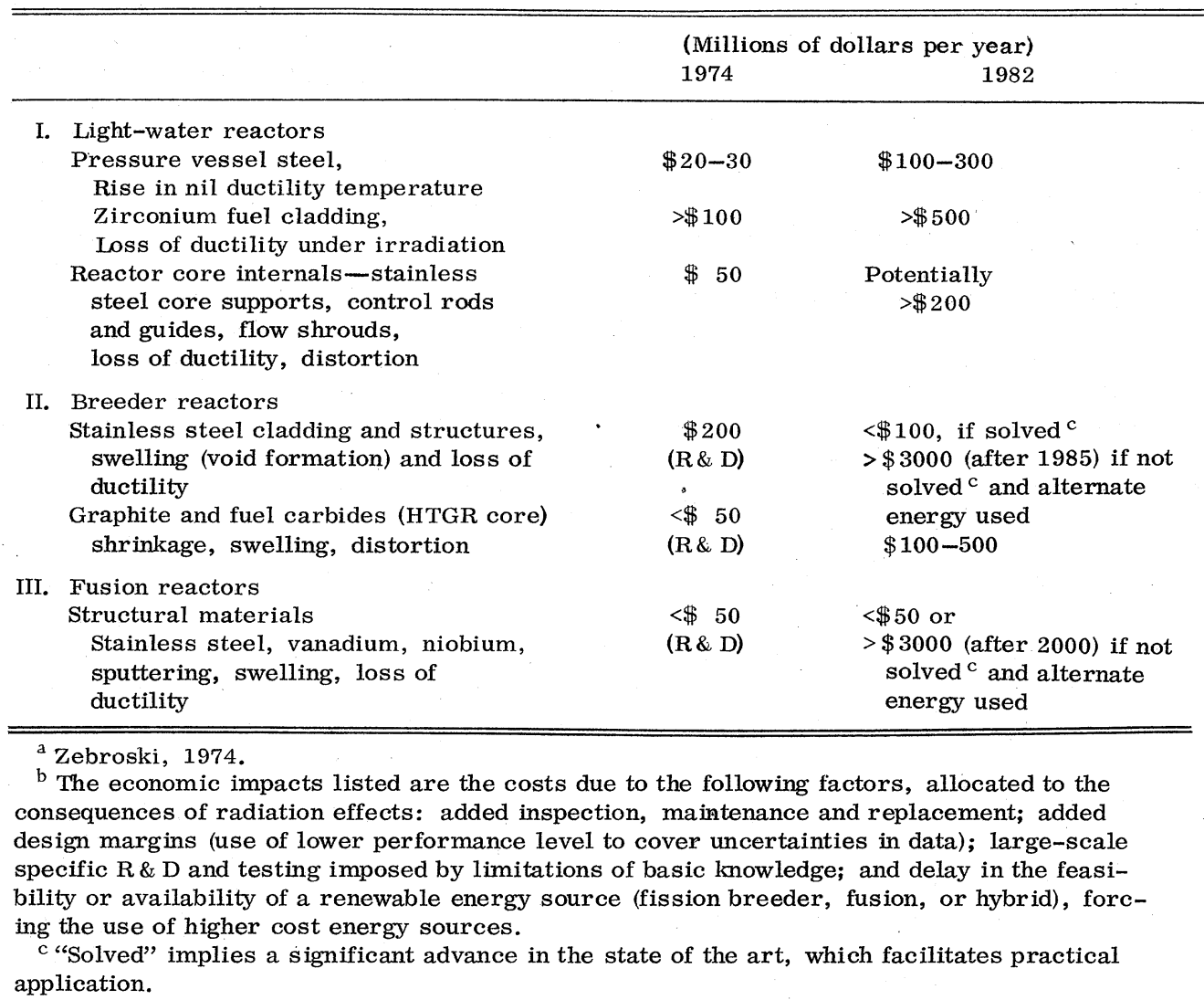

\section{a. Technological problems (see Sec. 11)}

\section{Controlled thermonuclear reactors (CTR)}

- - Gain an understanding of the effects of fusion reactor radiation on the mechanical properties of the plasma containment vessel (first wall) with particular emphasis on ductility, creep, stress rupture and fatigue life.

- Understand dimensional stability of the containment vessel material and the effect of high helium and hydrogen concentrations on the nucleation and growth of voids.

- Surface problems, insulator problems, and superconducting magnet problems are discussed respectively in Sections VIII, IX, and XI.

\section{Thermal reactors}

- - Improve the understanding of embrittlement in pressure vessel steels and fuel cladding materials.

\section{Fast breeder reactors}

- - Understand and reduce void swelling and radiation creep by developing resistant materials.

- Develop radiation damage models to allow use of neutron damage simulation techniques.

- Develop embrittlement resistant alloys through research into radiation embrittlement.

\section{b. Point defects in metals (see Sec. 111)}

- Investigate mechanisms of the interaction of point defects with each other, with impurities, with dislocations, and with strain fields.

- Confirm the properties of interstitials by physics experiments.

-Identify the defect responsible for recovery Stage

III and the associated defect processes.

- Catalogue the thermodynamic properties of point defects in all metals; give immediate emphasis to bcc (body centered cubic) metals.

- Develop new techniques for quantitative characterization of point defects and their clusters.

- Develop theoretical understanding of the relation of property change to defect concentration and state of aggregation for better identification and counting of defects.

\section{c. Voids and dislocations in metals (see Sec. IV)}

- Perform detailed experimental and theoretical studies to elucidate the mechanisms responsible for the nucleation and growth of voids in model fcc (face-centered cubic) and bcc alloy systems with specimens well-characterized from both a chemical and a microstructural point of view.

- Perform experiments on model fec and bec alloy 
systems to elucidate the mechanisms responsible for the saturation of void growth. The experiments should be performed on specimens well characterized chemically and microstructurally.

\section{d. Theory of damage production (see Sec. V)}

--Develop the theory of heavy ion simulation of neutron damage.

- - Improve the theory of effects of defects on mechanical properties.

- Study processes by which voids and dislocation loops are nucleated, including the roles of foreign atoms and stress.

\section{e. Simulation of reactor neutron damage (see Sec. VI)}

--Establish the range of validity (e.g., energy, displacement level, displacement rate, temperature) of ion and electron simulation techniques in providing an accurate means for anticipating fission and fusion neutron damage effects.

- - Devise techniques for simulation studies of changes in mechanical properties such as creep and embrittlement with and without externally applied stress. In addition to providing data more quickly, such simulation could provide information on stress enhanced effects.

- Devel op a wider range of ion beam facilities for simulation studies. These should include higher beam currents, a wider variety of ions and clean target systems in which accelerator contamination of refractory metal targets at high temperature can be avoided.

- Assess the need for simultaneous gas atom injection and ion beam irradiation as contrasted with preinjection.

- Establish the theoretical relationship between "free" defect concentrations (those defects surviving initial cascade recombination) associated with electron, proton, heavy ion, fission and fusion neutron bombardment (see Sec. V).

\section{f. Hydrogen and helium in metals (see Sec. VII)}

- - Develop an understanding of the effects of hydrogen on the mechanical properties of alloy systems. The effects of both solute hydrogen and hydrogen atmospheres must be considered.

- Establish the behavior of helium in solids and its effects on the mechanical properties using both theoretical and experimental methods. Interactions of helium with other defects must be understood.

\section{g. Interaction of surfaces with radiation (see Sec. VIII)}

- - Investigate charge exchange and the energy and particle reflection coefficients for $\mathrm{H}$ and $\mathrm{He}$ atoms and ions in the energy range from $100 \mathrm{eV}$ to $20 \mathrm{keV}$ for surfaces in ultra high vacuum, and also for surfaces covered with adsorbed hydrogen.
- Obtain a comprehensive understanding of the sputtering coefficients of refractory metals and high temperature insulators by hydrogen and helium ions from $100 \mathrm{eV}$ to $20 \mathrm{keV}$ for structurally well-characterized materials.

- Studies of neutron sputtering may be needed, but clarification of the experimental situation is needed to determine its importance.

- Understand the retention, diffusion, precipitation and re-solution of impurities at and near surfaces under bombardment by relatively low energy particles.

\section{h. Insulators (see Sec. IX)}

- Extend to high temperatures, high doses, and high fluxes studies of electrical, mechanical, and optical properties, as well as studies of the effects of radiation on processes such as diffusion and creep.

- Identify basic radiation-induced defects, their properties and their annealing characteristics, in insulators of interest.

- Investigate insulator crystal growth and characterization.

\section{i. Semiconductors (see Sec. $X$ )}

- Obtain further identification of defects and defect migration mechanisms.

- Improve the theory of defect production, energy states, defect migration, interaction, and formation.

- Further investigate ion implantation, and particularly dynamic rate effects as important and promising avenues of research.

\section{j. Superconductivity (see Sec. XI)}

- Measure the superconductor parameters $I_{c}, H_{c}$, and $T_{c}$ as a function of fluence, particularly at $4{ }^{\circ} \mathrm{K}$.

- Measure the recovery behavior of $T_{c}, I_{c}$, and $H_{c 2}$ after irradiation.

- Study the stability of sample coils irradiated at $4^{\circ} \mathrm{K}$ and compare the results with stability theories.

- Study irradiation effects in superconducting materials as a function of their crystal structure.

- Perform basic physical measurements on irradiated superconductors, e.g., heat capacity, resistivity and magnetic susceptibility.

- Study the influence of metallurgical variables (e.g., heat treatment, fabrication techniques, impurities) on the parameters of superconductors.

- Investigate the properties of magnetic fluxoids including the pinning of fluxoids by defects.

\section{k. Interactions between universities and laboratories} (see Sec. XII)

- Increase university-laboratory cooperation by joint research, summer programs, and interchange seminars. 


\section{TECHNOLOGICAL PROBLEMS}

\section{A. Controlled thermonuclear reactors}

\section{Introduction}

The proposed successor to the breeder reactor is the controlled thermonuclear fusion reactor. At the heart of such a reactor lies a plasma, probably of deuterium and tritium, which is heated to temperatures from 100 to 500 million degrees. In the deuterium-tritium (D-T) fusion reaction, $\mathrm{D}+\mathrm{T} \rightarrow{ }^{4} \mathrm{He}+n+17.6 \mathrm{MeV}, 80 \%$ of the energy released is carried by the $\sim 14 \mathrm{MeV}$ neutrons. There are many different materials in fusion reactors which will suffer radiation damage if a $D-T$ fuel cycle is used. Since $14 \mathrm{MeV}$ neutron sources for engineering testing are not expected to be readily available in the near future greater reliance and importance are placed on a fundamental under standing of radiation damage to materials of interest. Some examples of those materials are given in Table II. It is not possible to go into detail on the specific problems of the se materials. ${ }^{2}$ We will only discuss in this report what is commonly accepted as the most critical problem of fusion reactors; that is the material of the vessel which contains the plasma, i.e., the first wall material. Surface problems are covered in Sec. VIII. Other problems which concern electrical insulators and optical materials (for lasers) are discussed in Sec. IX. Superconducting magnet material problems are discussed in Sec. XI.

\section{Operating environment}

The environment which the CTR first wall materials will face is very much a function of two things: Reactor type (e.g., tokamaks, short pulsed reactors like the theta pinches or laser systems, and steady state devices like mirrors); and metal-coolant choice (e.g., steel-He or $\mathrm{Li}, \mathrm{Nb}-\mathrm{Li}, \mathrm{Al}-\mathrm{Al}_{2} \mathrm{O}_{3}-\mathrm{He}$, etc.).

We may obtain an approximate range of operating conditions from current designs by various laboratories. ${ }^{3}$ Table III lists a few of the more pertinent conditions. Note the wide range of temperatures and thermal pulses that typify current fusion reactor designs. Neutron fluences are time averaged values for $14 \mathrm{MeV}$ neutrons and total neutron spectra. Extremes in Table III correspond to $1-10 \mathrm{MW} / \mathrm{m}^{2}$ neutron wall loadings. Pulsed reactor operation results in high instanta-

${ }^{2}$ We call the reader's attention to the following references: (a) "Fusion Reactor First Wall Materials," edited by L. C. Ianniello, Report WASH-1206, 1972;

(b) Proceedings of the International Working Sessions on Fusion Reactor Technology, Oak Ridge National Laboratory, June 28-July 2, 1971, Report CONF-710624;

(c) "Technology of Controlled Thermonuclear Fusion Experiments and the Engineering Aspects of Fusion Reactors" edited by E. Linn Draper Jr., Austin Texas, Nov. 20, 1972, AEC Symposium Series 31, Report CONF-72111;

(d) G. L. Kulcinski, 1974, Radiation Damage by Neutrons to Materials in D-T Fusion Reactors, to be published in Proceedings of IAEA Conference on Plasma Physics and Fusion Technology Tokyo, Nov. 1974;

(e) Proceedings of the First Topical Meeting on the Technology of Controlled Nuclear Fusion Report CONF-740402-April, 1974, edited by G. R. Hopkins. neous atom displacement rates. Most reactors which operate on a steady state or "quasi steady state" basis have instantaneous displacement rates of $\sim 10^{-6} \mathrm{dpa} / \mathrm{sec}$ $(\mathrm{dpa}=$ displacements per atom $)$. Some reactors like the theta pinch reactors have instantaneous displacement rates $\sim 10^{-5}$ to $10^{-4} \mathrm{dpa} / \mathrm{sec}$. Laser systems have instantaneous displacement rates of $10^{-2}$ to $10^{-1} \mathrm{dpa} / \mathrm{sec}$ for the same average power level.

Gas generation rates are a function of the first wall material, but for a $1 \mathrm{MW} / \mathrm{m}^{2}$ neutron wall loading, the helium generation rate will vary from $\sim 30$ atomic parts per million (appm) per year for $\mathrm{Nb}$, to 600 appm for aluminum alloys (Kulcinski, et al., 1975). Similar numbers are given for hydrogen production.

The exact stress levels in fusion reactors again depend on design; but with the coolant pressures typical of liquid lithium and helium gas cooling, in addition to the thermal stresses arising from temperature gradients across the first wall, it is estimated that the stress levels will vary from 100 to 1000 bars (150015000 psi). Probably more serious than the absolute level of stresses is the fact that in all systems, except the mirror reactors, these stresses will be repeated many thousands to tens of millions of times per year. The exact value depends on the length of the burn cycle and the recharging time.

\section{Mechanical property damage}

Many of the mechanical property damage problems of fusion reactors are also common to thermal and fast breeder reactors. Ideally one would like the structural members of a fusion reactor first wall to retain the following properties during irradiation in order to as sure vacuum tightness for the plasma and containment of the reactor coolant: (i) reasonable ductility $(\geqslant 1 \%$ uniform elongation); (ii) low creep rate $\left(\leqslant 10^{-7} \mathrm{~h}^{-1}\right)$; (iii) acceptable stress rupture-life at reactor operating conditions $\left(\sim 10^{5} \mathrm{~h}\right)$; (iv) long fatigue life during $10^{4}$ to $10^{8}$ thermal cycles. These properties must be maintained even though every atom theoretically will be displaced over 10 times per year, large amounts of soluble and insoluble gas will be generated and the chemical composition of the material will be changing.

The present status of experimental and theoretical information on the effects of irradiation on the mechanical

${ }^{3}$ These designs are described in the following references:

(a) B. Badger et al., "A Wisconsin Toroidal Fusion Reactor Design," UWMAK-1, UWFDM-68, Nov. 1973;

(b) "An Engineering Design Study of a Reference Theta Pinch Reactor (RTPR)" LA-5336, ANL-8019, Joint Report of the Los Alamos Scientific Laboratory and Argonne National Laboratory (March 1974);

(c) J. Williams, T. Merson, F. Finch, F. Schilling, and T. Frank, 1974 in Proceedings of the First Topical Meeting on the Technology of Controlled Nuclear Fusion, Report CONF-740402-April, 1974, edited by G. R. Hopkins;

(d) R. W. Werner, G. A. Carlson, Jack Hovingh, J. D. Lee, and M. A. Peterson, Progress Report No. 1 on the Design Considerations for a Low Power Experimental Mirror Reactor UCRL-74054, Nov. 1972. 
TABLE II. Typical materials which will be damaged during operation in controlled thermonuclear reactors.

\begin{tabular}{|c|c|}
\hline Material function & Typical examples \\
\hline First wall and blanket structural components & $\begin{array}{l}\text { Austenitic stainless steels (304, 316, 347, etc.) } \\
\text { Nickel based alloys (PE16, Inconel, Incoloy, etc.) } \\
\text { Refractory metals }(\mathrm{V}, \mathrm{Nb} \text {, Mo, or alloys of those } \\
\text { metals with } \mathrm{Ti}, \mathrm{Zr} \text {, or } \mathrm{Cr}) \\
\text { Others [Sintered aluminum product (SAP), SiC, } \\
\text { graphite, etc.] }\end{array}$ \\
\hline Reflection, moderation & Graphite \\
\hline Neutron multiplication & $\mathrm{Be}, \mathrm{BeO}$ \\
\hline $\begin{array}{l}\text { Breeding } \\
\text { Radiation shielding }\end{array}$ & $\begin{array}{l}\mathrm{Li}, \quad \mathrm{Li}_{2} \mathrm{O}, \quad \mathrm{Li}_{2} \mathrm{Al}_{2} \mathrm{O}_{4}, \mathrm{Li}-\mathrm{Al} \text {, etc. } \\
\mathrm{B}, \mathrm{B}, \mathrm{C}, \mathrm{Pb} \text {, austenitic steel }\end{array}$ \\
\hline $\begin{array}{l}\text { Electric insulation (especially for pulsed } \\
\text { reactors) }\end{array}$ & $\mathrm{Al}_{2} \mathrm{O}_{3}, \mathrm{MgO}, \mathrm{Y}_{2} \mathrm{O}_{3}$ and others \\
\hline Optics for laser systems & $\begin{array}{l}\text { Windows: } \mathrm{Ge}, \mathrm{NaCl}, \mathrm{KCl}, \mathrm{GaAs}, \mathrm{CdSe} \text {, etc. } \\
\text { Chalcogenides (GaAs, CdSe, etc.) } \\
\text { Mirrors: } \mathrm{Al}, \mathrm{Al}-7178, \mathrm{Al}-\mathrm{Ni}, \mathrm{Be}-\mathrm{Ni}, \mathrm{Be}-\mathrm{Cu} \text { etc. }\end{array}$ \\
\hline Thermal insulation (for S/C magnets) & $\begin{array}{l}\text { Mirrors: Al, } \mathrm{Al}-7178, \mathrm{Al}-\mathrm{Ni}, \mathrm{Be}-\mathrm{Ni}, \mathrm{Be}-\mathrm{Cu} \text {, etc. } \\
\text { Mylar or other hydrocarbons }\end{array}$ \\
\hline Superconducting magnet filaments & $\mathrm{NbTi}, \mathrm{Nb}_{3} \mathrm{Sn}, \mathrm{V}_{3} \mathrm{Ga}$, etc. \\
\hline Superconducting stabilizing materials & $\mathrm{Cu}, \mathrm{Al}$ \\
\hline Magnet support structure $\left(<10^{\circ} \mathrm{K}\right)$ & Austenitic steels \\
\hline
\end{tabular}

properties of potential CTR materials is certainly marginal at best. The first obvious fact that emerges from a review is that there are no known experimental data on the effects of $14 \mathrm{MeV}$ neutron damage $\left(>10^{17} \mathrm{n} / \mathrm{cm}^{2}\right)$ on the high temperature mechanical properties of potential CTR materials. However, a large body of information does exist on the stress-rupture ductility of a few materials irradiated with fission neutrons (e.g., 304-SS, 316SS, PE 16, graphite) up to $\sim 10^{23} \mathrm{n} / \mathrm{cm}^{2}$.

Experimental data pertaining to the fatigue failure of irradiated metals are almost nonexistent. The existing data are usually from post irradiation tests where the damage state is not the same as it would be during cyclic stress in a reactor.

The theoretical explanations for the effects of radiationproduced defects on the mechanical properties of metals are not very well developed, nor do they allow extrapolation from the present fission reactor data to $14 \mathrm{MeV}$ neutron damage. We do know that high temperature creep-ductility values for steels and $\mathrm{Ni}$-based alloys drop to the $1 \%$ level after fission neutron fluences of $\sim 3-5 \times 10^{22} \mathrm{n} / \mathrm{cm}^{2}$ and associated helium concentrations of 10-20 appm. It is also known that the stress-rupture life of steel is very strongly reduced at irradiation tem - peratures above $550^{\circ} \mathrm{C}$ due to helium bubble formation and accumulation at internal surfaces such as grain boundaries.

The refractory metals also show a loss of ductility from helium gas bubble accumulation. In addition, it has been known for some time that the nil ductility temperature of bcc metals is very sensitive to irradiation. Normally the nil ductility temperature of refractory metals is below room temperature, but it is possible to raise it above room temperature by modest irradiations $\left(10^{20}-10^{21} \mathrm{n} / \mathrm{cm}^{2}\right)$. The significance of this shift is that while most refractories can operate in a ductile fashion at high temperature, lowering of the temperature during reactor cycles or normal maintenance may initiate brittle failures. This effect is particularly acute in Mo alloys, but it applies to $\mathrm{V}$ and $\mathrm{Nb}$ alloys as well.

Finally, the theoretical basis for fatigue failures even in fission neutron irradiated metals is not well understood. Part of this stems from lack of experimental facilities to superimpose the proper conditions on the ir radiated metal, and part of it comes from the fact that such fatigue problems are not incurred in fission reactors which operate in "steady state." It is not possible to extrapolate the small amount of present data on fa-

TABLE III. Range of operating conditions envisaged for the first wall components of fusion reactors.

\begin{tabular}{ll}
\hline \multicolumn{1}{c}{ Parameters } & \multicolumn{1}{c}{ Value } \\
\hline Temperature ${ }^{\circ} \mathrm{C}$ & $300-1000$ (steady state) \\
& $\Delta T \approx 50-300$ (thermal pulse) \\
Neutron exposure $\left(\mathrm{n} / \mathrm{cm}^{2}-\mathrm{yr}\right)$ & $10^{21}-10^{22}$ a (14.1 MeV) \\
& $10^{22-10^{23} \text { (total) }}$ \\
Damage rate (dpa/sec) & $10^{-6}-10^{-1}$ \\
Gas generation rates (appm/yr) ${ }^{\mathrm{b}}$ & $75-500$ (hydrogen) \\
Stress levels-bars (psi) & $30-600$ (helium) \\
& $100-1000$ \\
Number of cycles (excluding mirrors) $\left(\mathrm{yr}^{-1}\right)$ & $(1500-15000)$ \\
\hline \hline
\end{tabular}

${ }^{\mathrm{a}}$ Values correspond to 1 and $10 \mathrm{MW} / \mathrm{m}^{2}$ wall loadings.

b $1 \mathrm{MW} / \mathrm{m}^{2}$ only, 10 times that number for $10 \mathrm{MW} / \mathrm{m}^{2}$. 
tigue life to irradiation with $14 \mathrm{MeV}$ neutrons, but it seems certain that the fatigue life will not improve over fission neutron data per unit of damage.

\section{Dimensional stability}

The swelling of metals and nonmetals (e.g., graphite, $\mathrm{SiC}$ ) is well known from recent fission reactor work. This swelling not only represents a problem from the standpoint of volume changes, but the existence of swelling gradients can impose severe stresses on rigid reactor components. These stresses can result in warping or cracking of relatively thin first wall structures. It is easily seen that the problems of swelling and mechanical properties cannot be completely decoupled.

Swelling in first wall components at typical operating conditions can come from at least four different sources:

(i) Distortion of the lattice due to the generation of isolated point defects. This effect is negligible in metallic components but may be of considerable importance in SiC and graphite at high temperature.

(ii) Collection of interstitials into dislocation loops and of vacancies into voids. This is the major swelling mechanism in metallic components.

(iii) Production of gas atoms and formation of gas bubbles. This may be a particular problem in $\mathrm{Al}, \mathrm{C}$, $\mathrm{SiC}$ or $\mathrm{Al}_{2} \mathrm{O}_{3}$.

(iv) Transmutation reactions which produce atoms which are larger than original atoms. One example of this effect is the production of $\mathrm{Zr}$ in $\mathrm{Nb}$, but it will occur in practically all CTR materials.

Ideally, one would like to set limits on the maximum swelling (or swelling gradient) that could be tolerated, and then try to correlate that limit with experimental data or theoretical predictions. Roughly speaking, a maximum tolerable limit may be $\sim 10 \%$ swelling and one would not like to exceed swelling gradients of $1 \%$ per $\mathrm{cm}$ until more detailed design and stress analyses are completed.

A large body of data exists on the effect of fission neutron damage and irradiation temperature on the swelling of SiC and graphite. There are no known data on the swelling of these materials at high temperature as a result of $14 \mathrm{MeV}$ neutron damage.

The mechanism for swelling in SiC and graphite is fairly well understood. The production, migration and preferential agglomeration of point defects on different crystallographic planes appears to account in principle for the observed swelling. In most cases, the starting material is not $100 \%$ dense so that the material is initially densified until all of the space is occupied. After the void space is used up, further irradiation can cause a phenomenon called "break away swelling" which can lead to ver y severe distortions. The threshold for "break away swelling" is temperature sensitive but it generally occurs in the neighborhood of $2-3 \times 10^{22} \mathrm{n} / \mathrm{cm}^{2}$ of fission neutron damage. Some progress is being made in developing isotropic graphite and SiC to alleviate this problem, but it appears very difficult to obtain a material which will stand neutron fluences of $>10^{23}$ $\mathrm{n} / \mathrm{cm}^{2}$ (Engle and Eatherly, 1972).
There are currently three methods of investigating void swelling in metals: fission neutrons, charged particle bombardment, and high voltage electron microscopy (HVEM). The reasons for void formation and growth are fairly well understood although nucleation mechanisms are still somewhat vague. More detail on this subject can be found in Sec. IV, on voids.

There is a large body of experimental information on the stainless steels and nickel base alloys from fission reactors, ion bombardment, and HVEM studies (Irradiation Produced Voids, 1975). Much less information is available on the refractory metals. There is little information on the swelling of sintered aluminum products (SAP), although irradiation of other Al alloys reveals high levels of swelling.

The nucleation and growth of gas bubbles in metals has been studied for over 15 years and the swelling mechanisms are fairly well understood. The gas bubbles expand by collecting vacancies in the solid which have been produced thermally or by irradiation. There is not very much information on the combined effects of high gas generation rates and high damage rates $\left(\sim 10^{-4}\right.$ $10^{-1} \mathrm{dpa} / \mathrm{sec}$ ) but such results should be predictable from current models.

\section{Required information}

The main requirements for future work can be divided into the different areas listed below.

(i) Comparison of $14 \mathrm{MeV}$ neutron displacement damage to fission reactor and heavy ion damage. It is of paramount importance to determine if $14 \mathrm{MeV}$ neutron displacement damage is simply an extension of fission reactor damage when appropriate interaction cross sections are taken into account. For example does the increased displacement spike size or structure facilitate or retard the formation of microstructural defects such as loops, voids, or precipitates, which in turn will greatly influence the strength of metals? It is also necessary to test the validity of using charged particle bombardment to simulate displacement damage in CTR materials. Such studies are of a fundamental nature and could be done with existing sources.

(ii) Investigations of the synergistic effects of helium and hydrogen on displacement damage produced by neutrons and on the nucleation and growth of voids should be pursued. It is important that gas atoms be added to the solid in direct proportion to the displacement damage predicted by theory in a fusion reactor. Samples, pre-injected with hundreds if not thousands, of ppm gas before irradiation will not necessarily give the same result at high temperature as gas generated monatomically with damage. It is known that such preinjection can significantly alter the spatial distribution and size of defects which in turn can influence the movement of dislocations in the solid.

Simulation studies with ion bombardment and intermittent or continuous gas injection look feasible provided a reasonable correlation can be obta ined between ion bombardment and $14 \mathrm{MeV}$ neutron irradiation. HVEM damage simulation may help in this area, but care should be exercised in the interpretation of the results due to 
the vastly different nature of displacement spikes (thousands of atoms/neutron versus one or two atoms per electron). The effects of helium bubble swelling in graphite, SiC, and a few alloys like SAP (sintered aluminum product) or stainless steel need to be inves tigated. Such work can be accomplished with current simulation techniques and careful attention paid to damage rate effects.

The mobility of neutronically generated gases and their collection at grain boundaries must be thoroughly investigated. If alternative experiments and theoretical interpretation are not sufficiently conclusive such work will require expensive, high temperature, 14 $\mathrm{MeV}$ neutron test facilities which produce fluxes of $10^{13}-10^{15} \mathrm{n} / \mathrm{cm}^{2}-\mathrm{sec}$.

(iii) The effect of displacement rate on the microstructural distribution of defects and on void nucleation and growth must be understood. This effect is very important for pulsed reactor systems such as the theta pinch and laser fusion reactors. Evidence from charged particle simulation studies reveals that the denuding of damage around internal surfaces such as grain boundaries or precipitates is substantially reduced at higher dpa rates. Such effects might alter the failure mechanism at the grain boundaries. It is also important to understand the effects of the relatively long $(0.1-10 \mathrm{sec})$ annealing times between burns in pulsed reactor systems.

It is known that under increased damage rate conditions, the rate of recombination between vacancies and interstitials greatly increases. Increased recombination has the effect of reducing the supersaturation levels and hence the amount of void swelling. It is therefore possible that pulsed reactors will have different void swelling characteristics than steady state systems at the same temperature. This particular problem can be addressed by current ion bombardment techniques which can vary the displacement rate from $10^{-6} \mathrm{dpa} / \mathrm{sec}$ to $10^{-1} \mathrm{dpa} / \mathrm{sec}$ simply by controlling the particle output from high energy accelerators. If alternative experiments and theory are not conclusive this work will require an expensive source of $\sim 10^{14} \mathrm{n} / \mathrm{cm}^{2}-\mathrm{sec}$ with instantaneous neutron fluxes of $10^{15}-10^{19} \mathrm{n} / \mathrm{cm}^{2}-\mathrm{sec}$. The pulse frequency must be of the order of once every ten seconds to ten times a second.

(iv) It is also necessary to understand the effect of nongaseous transmutation products on the microstructure of the damage state and on the formation of voids. In metals like $\mathrm{Nb}$, the concentration of the major transmutation product, $\mathrm{Zr}$, may actually exceed the solubility limit in the host metal. A similar situation exists for the production of Si in Al. Precipitation of second phases can drastically alter the mechanical properties by producing barriers to dislocation motion, and, in some cases, causing dislocation pile-up, often a precursor to crack formation. The production of $\mathrm{Cr}$ in $\mathrm{V}-\mathrm{Ti}$ alloys, or the production of $\mathrm{Mn}, \mathrm{Ti}$, and $\mathrm{V}$ in 316 SS may also alter the creep-rupture properties even though the above elements are soluble in the host metal (Irradiation Produced Voids, 1975).

The effect of nongaseous transmutation products on the formation of voids in metals should be measured. It is known that void swelling tends to decrease with additions of impurity elements in most metals. The continuous generation of new elements in irradiated CTR materials may alter the swelling behavior. Such effects might not be observed in fission reactor, ion bombardment or HVEM work unless care is taken to irradiate a wide series of alloys.

(v) We must mount a concerted effort towards the theoretical understanding of the effects of $14 \mathrm{MeV}$ neutrons on the mechanical properties of materials. For example, most of the present fusion reactor designs are sorely lacking in the assessment of the fatigue life time that might be expected under large stress, strain and thermal excursions. A large part of the theoretical model work can be, and is being, pursued in the various fission reactor programs of the world. It is recommended that these programs be closely monitored for progress and that solid state theorists be brought into the CTR program. Further work on understanding the irradiation effects on the DBTT is necessary if we are to use bcc metals in fusion reactors. Theoretical efforts should also be directed toward analyzing the effect of defect annealing between $\mathrm{D}-\mathrm{T}$ fusion cycles, in pulsed devices.

(vi) The effect of stress, either static or cyclic, on swelling must be understood in more detail. This is even more critical in fusion than in fission reactors because of the pulsed nature of most fusion reactors. The movement of dislocations through pinning sites will alter the microstructure such that void nucleation may be diminished (or enhanced?). The theoretical foundation of this subject is sorely lacking and must be developed before future reactor studies can progress to the design stage.

(vii) More information on the allowable swelling and swelling gradients in severely embrittled material must be forthcoming. Present design limits require that the first wall be changed about every five years or so with the associated cost and environmental penalties that must be paid. If detailed stress analysis raises or lowers the presently used design limits, then whole design concepts may change. These calculations could be performed now and more definitive design limits might be stated for future reactor studies.

(viii) It will be necessary to investigate the effects of $14 \mathrm{MeV}$ neutron irradiation on the "runaway" swelling phenomena in SiC and graphite if these materials are ever to be used for first walls of CTRs. The effect of extremely high helium concentrations (the helium production cross section for carbon is $\sim 100$ times that of $\mathrm{Nb}$ ) on the fluence threshold of this effect is also needed. Damage rate studies may also be required if $\mathrm{SiC}$ and graphite are used for first walls of pulsed systems. The above work requires a neutron source of $\sim 10^{15}$ $\mathrm{n} / \mathrm{cm}^{2}-\mathrm{sec}$ if damage levels of $10^{23} \mathrm{n} / \mathrm{cm}^{2}$ are to be reached in reasonable times. Provisions also need to be made for heated specimens.

(ix) Finally, because reasonable size $14 \mathrm{MeV}$ neutron sources will probably not be available in the next 5 to 10 years, we must obtain as much data as possible from fission reactors and simulation studies. Efforts will have to be made to simulate reasonable CTR environments by clever design of test capsules and perhaps recycling specimens several times after modification for 
transmutation reactions. A large variety of materials should be screened by simulation studies when possible so that more valuable core space can be used for those materials which are truly high on the priority list.

An effort should be made to test the properties in situ when possible if any realistic assessment of their engineering usefulness is to be made. Post irradiation tests can reveal the gross features of damaged material, but cannot be relied upon for dependable quantitative results. Experience from fission reactor work clearly showed that post-reactor creep studies could not predict in-reactor properties nor could they be particularly helpful in developing theoretical models. In addition, such in-reactor testing at high temperatures requires a volume of the order of $\sim 10 \mathrm{~cm}^{3}$ per sample in test facilities. Several alloy systems may have to be tested and 10 to 100 specimens of each alloy may be required if reasonable statistics are to be developed. Therefore it is not sufficient to produce $10^{14}-10^{15} \mathrm{n} / \mathrm{cm}^{2}-\mathrm{sec}$ fluxes in a volume of only $1-2 \mathrm{~cm}^{3}$. Test facilities should be designed to utilize much larger test capsules.

\section{B. Thermal reactors}

The thermal neutron power reactors now in service could operate much more efficiently and at lower cost if it were not necessary to make allowances in the reactor design for the fact that the pressure vessel and the fuel cladding are subject to radiation embrittlement.

The pressure vessel is irradiated by both fast and thermal neutrons, which results in an increase in the nil ductility temperature. This is the temperature below which failure would be by brittle cleavage. Above the nil ductility temperature, failure is by ductile tearing. The obvious danger lies in the fact that pressure vessels can become brittle at room temperature or even at the reactor operating temperature, leading to the possibility of failure of the vessel. The lack of understanding of this embrittlement, both the phenomenon itself and the changes due to radiation damage, has led to a monitoring program which involves periodic physical inspections of the vessel together with the testing for embrittlement of small steel samples located on the vessel walls. Both this surveillance program and the fact that these reactors must operate under less

${ }^{4}$ Reviews of technological problems faced in the design of thermal reactors discussed in Sec. II.B and of fast breeder reactors, discussed in Sec. II.C included the following:

(a) "Irradiation Effects in Structural Alloys for Thermal and Fast Reactors," ASTM Symposium, San Francisco, 1968, Special Technical Publication 457, (ASTM, Philadelphia, 1969);

(b) "Symposium on Materials Performance in Operating Nuclear Systems," edited by M. S. Wechsler and W. H. Smith, Ames, Iowa, Conference, 1973 (USAEC, TN 37830);

(c) H. Bethe, "Advanced Nuclear Power, Report of the Cornell Workshops on the Major Is sues of a National Energy Research and Development Program," (Cornell University, Ithaca, 1973);

(d) Publication Hearings on the "Key Issues Related to LMFBR Development," National Science Foundation, Fission Energy Working Group, Chicago (August 14, 1974);

(e) LMFBR Program Plan: Fuels and Materials, WASH-1107 (2nd ed), December 1972. than optimal conditions because of this safety hazard are expensive; it is estimated that their cost to the power industry will be $\$ 100$ to $\$ 300$ million annually by 1982. Although new steels that are more resistant to e mbrittlement are being developed, the problem is still a very important one both in relation to the safety of existing reactors and the reduction of safety tolerances in new reactors. Thus research on radiation embrittlement of steels can have important consequences for the safe operation of reactors under more efficient conditions.

Consider now the embrittlement of fuel cladding. The cladding, a zirconium alloy, is subjected to a higher neutron flux, $\sim 10^{13} \mathrm{n} / \mathrm{cm}^{2}-\mathrm{sec}$, and the principal effect of the radiation damage is a loss in ductility. This embrittlement increases the frequency of cladding rupture, leading to the possible release of radioactivity to the primary cooling circuit. It is frequently necessary to replace ruptured fuel elements prior to optimum fuel burnup, resulting in inefficient operating conditions. Improved understanding of the radiation embrittlement of the fuel cladding material which would lead to an embrittlement resistant material would have important consequences for more economical reactor operations.

\section{Fast breeder reactors}

The fast neutron fluxes to be expected in a typical fast breeder reactor are about $10^{16} \mathrm{n} / \mathrm{cm}^{2}-\mathrm{sec}$, compared to fluxes of a few times $10^{13}$ in thermal reactors. This high fast flux, and higher fast fluences for fast breeder fuel assemblies will lead to materials problems not previously experienced or anticipated. In addition, those problems encountered in thermal reactors, such as loss in ductility, will be much more serious and will have a more pronounced effect on the economic viability of breeder reactors.

The most crucial materials problem in fast breeder reactors at the present time is swelling associated with void formation. This phenomenon is discussed in detail in Sec. IV, on "Voids and Dislocations." At the high fluxes in these reactors there is a rapid generation of vacant lattice sites and interstitial atoms. At the reactor ambient temperatures these defects are mobile and the great majority recombine, but the annihilation is not complete and a steady state supersaturation of vacancies and interstitials occurs. The excess interstitials cluster into platelets which collapse to form dislocation loops. An appreciable number of the vacancies nucleate (probably on impurity gas atoms) three-dimensional precipitates called voids, which are easily observable with transmission electron microscopy. Consequently the metal swells, and volume swelling of approximately $20 \%$ has been observed in reactor components irradiated to neutron doses which would be accumulated during their expected lifetime in the reactor. The void swelling has particularly serious effects on the breeding process. The fuel pins have to be more widely spaced to provide sufficient cooling as they swell. Also, the nonuniformity of the neutron flux results in nonuniform swelling, causing the fuel pins to bow, and the density of fuel in the reactor core must be reduced further. This decrease in core density reduces the av- 
erage energy of the neutron spectrum resulting in a substantial decrease in the breeding ratio.

The development of swelling resistant materials will play an important role in the development of breeder reactors. Several possibilities to control the void swelling exist. For example, the annihilation process can be more highly favored through the retention of interstitial atoms by trapping them at precipitates or impurity atoms. Alternatively, it may be possible to force the vacancy clusters to form dislocation loops instead of voids. In any event it is clear that this is an area where clever research can have important effects on reactor technology.

Another area where fundamental information can be of great assistance is in the development of a radiation damage model which will permit the simulation of the large neutron fluxes and neutron doses encountered in fast breeder reactors by the use of heavy ion or electron bombardment (high voltage electron microscope). The void swelling, which occurs in years in existing steady state reactors such as the experimental breeder reactor, EBR2, in principle can be produced in hours by these charged particle bombardments. The difficulty in properly assessing the results in terms of neutron bombardment lies in accounting for the differences in displacement cascade effects; in the kinetic effects due to the much higher defect production rates, and in effects of $(n, p)$ and $(n, \alpha)$ reactions. This is obviously an area where fundamental concepts play an important role.

Alteration of mechanical properties during irradiation and as a result of the total irradiation ranks with dimensional instability as a major concern. Irradiation creep, stress effects on swelling, and thermal creep are deformation mechanisms that control the behavior of the reactor core. It is essential that these deformation mechanisms be understood in terms of their dependence on temperature, flux, fluence, stress, etc. Reduction of ductility due to reduced uniform strain at temperatures below about $500^{\circ} \mathrm{C}$ (in steels) and due to enhanced intergranular fracture above $500{ }^{\circ} \mathrm{C}$ may become a limiting factor. Extremely low fracture strains (near zero) are observed after irradiation to fluences of $10^{23} \mathrm{n} / \mathrm{cm}^{2}$. Of particular concern is the behavior under short-time temperature transients.

Progress in this area is hindered by a lack of understanding of the controlling deformation and fracture mechanisms in the absence of radiation, and even less understanding of the effect of irradiation produced defects on these mechanisms or in changing the mechanisms. This area can be divided into two parts: dynamic or in situ effects during irradiation and post-irradiation properties. Much more is known by far about the latter. Both areas are important in determining the usefulness of a given metal or alloy for a reactor core component. The dynamic behavior determines the response of the component to other radiation-produced changes (i.e., the creep rate and rupture ductility may be increased while the material is being irradiated so that the swelling can be accomodated). The post-irradiation properties probably determine the limits of degradation of mechanical properties and define the properties that will be present during transient changes in the core.

Particular problems that have been identified are radiation creep, the deformation under the action of an applied stress during irradiation; effects of irradiation on thermal creep; radiation hardening, the increase in yield strength after irradiation to high fluences; and elevated-temperature fracture, the reduction in ductility after irradiation to high fluences which of ten results in intergranular fracture. The loss of ductility is a more severe problem in the fast breeder reactors than in the thermal reactors because of the enhanced flux. 


\section{POINT DEFECTS IN METALS}

\section{A. Introduction}

When metals are irradiated with energetic particles, intrinsic point defects, i.e. interstitials and vacant lattice sites, are initially created. In neutron irradiations, transmutations will also be produced, resulting in a buildup of extrinsic point defects during an irradiation. Both intrinsic and extrinsic point defects affect the properties of metals. Some of the intrinsic defects annihilate by recombination, others aggregate into clusters of like kind or interact with impurities initially in the metal or with the transmutation products. The ability of the defects to migrate and thereby to cluster or to form defect-impurity complexes depends upon the temperature of the metal. Moreover, rate processes of great technological significance such as nucleation, precipitation, and segregation are diffusion controlled, and diffusion can be enhanced by the presence of a supersaturation of mobile defects. The degree of supersaturation is a function of dose rate and temperature. The extent to which a change in a rate process is significant depends upon the duration of exposure to radiation. Therefore, kinetic processes are governed not only by the fundamental parameters of point defects but also by the important controllable factors of irradiation temperature, flux and integrated flux (dose or fluence).

In order to understand radiation damage it is neces sary to be able to measure the number of defects produced during an irradiation, to understand the mechanisms of motion and clustering of the defects, and to measure their thermodynamic properties. It has become clear that the various types of defect clusters have significant effects on technologically important properties. Because clusters are built up of point defects, it follows that an understanding of the basic physics of point defects will aid in the solution of present and future technological problems related to radiation damage.

\section{B. Present status of knowiedge}

Many experimental techniques have been developed for investigating point defects in metals. A combination of all of these techniques has proved to be necessary in arriving at unique answers to questions concerning defect properties. We have now deduced a reasonable model for point defects in some metals which is consistent with the information obtained from all techniques. From electrical resistivity recovery data, annealing stages were established corresponding to the thermally activated migration and recombination of point defects in different initial spatial configurations. In past years the major experimental and theoretical emphasis has been devoted to identifying the defects responsible for each of these recovery stages. A brief description of these stages and the current status of our knowledge about them is given below.

Stage I: This stage occurs in most metals in the temperature range from $5^{\circ}-50^{\circ} \mathrm{K}$. It corresponds to the mutual annihilation of close pairs of vacancy and inter- stitial atoms, and to the annihilation of vacancies with freely migrating interstitials. Because of the relative simplicity of the processes involved, Stage I recovery is better understood than the recovery in other stages. The configuration of the interstitial and its dynamic motion have been established by diffuse $\mathrm{x}$-ray scatter ing, elastic constant, Mössbauer and annealing kinetics measurements combined with computer simulation studies. A few metals do not exhibit such an annealing stage, and this is a remaining puzzle. The absence of Stage I recovery is apparently not correlated with the crystal structure or any other simple characteristic of the se metals.

Stage II: Recovery in the temperature range from $50^{\circ}-200^{\circ} \mathrm{K}$ is defined as Stage II. It is attributed to trapping and de-trapping of migrating interstitials at impurity sites, and to clustering of interstitials to form interstitial loops. The latter phenomenon was recently established by diffuse $x$-ray scattering measurements on electron-irradiated metals at low temperatures. Details of the clustering mechanism are not understood; in particular the driving force for clustering is ill defined. Similarly, interactions between interstitials and impurities are poorly understood.

Stage III : This stage generally occurs in the range from approximately $200^{\circ}$ to $350^{\circ} \mathrm{K}$. It is presumed to be associated with the annihilation of interstitials in clusters by vacancies which migrate to them, and by vacancy aggregation to for $m$ vacancy loops. However, the processes which occur in this stage are controversial, and subject to reinterpretation. Some experiments performed in this temperature range are subject to dual interpretation in terms of vacancies or interstitials.

Stage IV: This stage is not universally found in metals. Most probably it exists when special impurity-vacancy interactions occur in a given metal or dilute alloy system.

Stage V: This is a broad high temperature stage in which numerous processes can occur. For example, dislocation loops can dissolve or annihilate through evaporation of vacancies, interaction with one another or with other types of dislocations in the lattice. Transmission electron microscopy and $x$-ray scattering techniques have been used to establish these processes.

Complete reviews of our present status of knowledge can be found in the recent technical literature (Vacancies, 1970; Point Defects, 1973).

\section{Basic areas of uncertainty}

(1) The defect responsible for Stage III and the associated processes remain to be unequivocally identified.

(2) Interactions of point defects with one another and with impurities such as transmutation products are poorly understood.

(3) Interactions of point defects and point defect clusters with extended defects, e.g., dislocations, stacking faults, grain boundaries, etc. have not been sufficiently investigated to explain observed phenomena.

(4) Mechanisms of cluster and loop growth as well as the migration of loops are only qualitatively understood, 
primarily because simple interactions between point defects are not totally explained.

(5) Few theories exist which correctly and quantitatively relate property changes such as those observed in electrical and thermal resistivity, lattice parameter, yield stress, hardness, etc., to the concentration and state of aggregation of defects.

\section{Promising areas of research}

(1) Unequivocal identification of the defect responsible for Stage III and its associated defect processes will clarify a long standing controversy and facilitate the interpretation of many puzzling experimental results.

(2) Experiments must be devised to substantiate the properties of interstitials in the lattice. For example, diffusion mechanisms in solids of different crystal structure are open to question, and the lattice dynamical properties of interstitial atoms are just now coming under investigation. The latter play an important role in determining the mechanical properties of irradiated metals. Extrinsic interstitial atoms such as $\mathrm{H}, \mathrm{He}, \mathrm{C}$,
$\mathrm{N}$ and $\mathrm{O}$ govern many processes of metallurgical and technological significance.

(3) Proposed mechanisms of interaction between point defects are not adequate to explain existing results and further theoretical and experimental research is required.

(4) Because point defects are of fundame ntal importance as the basic constituents of more complex defects, point defect parameters should be well established. A catalogue of the thermodynamic properties of point defects such as vacancy formation energies, vacancy and interstitial migration energies, point defect-impurity binding energies, etc., should be built up with immediate emphasis on bcc metals.

(5) New techniques for quantitative characterization of point defects and their clusters are always in demand, and should be immediately exploited when encountered. At the same time, theoretical understanding of the relationship between a property change and the point defect concentration and state of aggregation needs to be greatly improved for essentially all of the standard property-change measurements. 


\section{VOIDS AND DISLOCATIONS IN METALS}

\section{A. Introduction}

The swelling of metals that are subjected to a high fluence of fast neutrons at elevated temperatures $(0.3$ to 0.6 of the absolute melting point of the metal) was an unexpected physical phenomenon that was first discovered by Cawthorne and Fulton (1966). These investigators found that austenitic stainless steel fuel cladding subjected to a high fluence of fast neutrons in the Dounreay Fast Reactor in Great Britain contained a microstrueture which consisted of empty cavities (hereafter called voids) which were approximately $100 \AA$ in diameter. Since that time much experimental research has shown that voids are a general result of irradiating metals in certain temperature ranges to the point where every atom has been displaced a minimum of between 1 to 10 times. The macroscopic swelling (often exceeding $10 \%$ ) that accompanies the formation of these microscopic voids is a serious technological problem in the economic design and operation of a liquid metal fast breeder reactor (LMFBR) as well as in the case of a gas-cooled fast breeder reactor and the controlled thermonuclear fusion reactor. The phenomenon of void formation in irradiated metals has been the subject of three recent international conferences and several review articles. The reader is referred to these proceedings and articles for the myriad of details that by necessity must be omitted from the present discussion. ${ }^{5}$

A basic requirement for the nucleation and growth of voids is the existence of a preferential sink (attracts one defect preferentially), as well as a neutral sink (attracts vacancies and self-interstitials equally), for one of the two mobile point defects (vacancy or selfinterstitial atom) produced by the irradiation particle. It is now generally believed that the edge dislocation acts as a preferential $\operatorname{sink}^{6}$ for the self-interstitial atom (SIA). The larger strain field associated with the SIA, when compared to the strain field of the vacancy, results in a preferential drift of the SIAs to the edge dislocation.

${ }^{5}$ The conference proceedings can be found in the following:

(a) Voids Formed by Irradiation of Reactor Materials, Proceedings of a conference held in Reading England, March 24-25, 1971, edited by S. F. Pugh, M. H. Loretto, and D. I. R. Norris, British Nuclear Energy Society;

(b) Radiation Induced Voids in Metals, Conference held in Albany, N. Y., June 9-11, 1971, edited by J. W. Corbett and L. C. Ianniello, AEC Symposium Series 26 (CONF710601);

(c) The Physics of Irradiation Produced Voids, Proceedings of Consultants Conference on Void Formation, Harwell England, September 9-11, 1974, edited by R. S. Nelson, AERE Report R7934, 1975.

The review articles include: D. I. R. Norris, 1972, Radiat. Eff., 14, 1; D. I. R. Norris, Radiat. Eff. 15, 1, and R. Bullough and R. S. Nelson, 1974, Physics in Technology, 5, 29.

${ }^{6}$ This statement assumes that the climb of edge dislocations in this situation is diffusion-limited and not absorption-limited. If the supersaturation of vacancies and SIAs is low enough then the climb processes can become absorption-limited. In this case the edge dislocation can still act as a preferential sink if its absorptive properties are different for either the vacancy or the SIA.
Direct experimental evidence for this effect has been found in the high voltage electron microscope (HVEM) work of Norris (1971). The presence of a biased sink for SIAs and at least one neutral sink is a very basic requirement for void growth, and hence even though the experimental effort has been placed on voids it is the existence of edge dislocations that makes possible void growth. The general physical picture of the formation of voids is as follows. The incident radiation produces vacancies and SIAs in equal numbers and if the specimen is at a temperature where both types of point defects are mobile and where the lattice is also supersaturated with respect to both species then one has met the first condition for void nucleation and growth. Next since the SIAs are more mobile than the vacancies they will cluster in the form of dislocation loops which are usually of the pure edge type. The small net flux of SIAs to edge dislocation loops also means that the point defect flux into any other neutral sink will be vacancy in nature. Thus any void nuclei that have formed may grow, as long as the lattice is supersaturated with respect to vacancies. Continued particle irradiation results in the additional growth of the interstitial edge dislocation loops into a three-dimensional dislocation network. The voids will then continue to grow as long as no mechanism exists which results in the recombination of the equal numbers of vacancies and SIAs produced. Therefore all mechanisms which produce a saturation in the void growth must involve a means of making the vacancies recombine with the SIAs before they lose their point defect character. With the above as an introduction to the general problem we now proceed to specific problem areas.

\section{B. Nucleation problems}

The nucleation problem is really twofold, since it is clear that we must consider the nucleation of both interstitial edge-dislocation loops and voids. Mechanisms for void nucleation have been given the most attention both theoretically and experimentally and much of the experimental evidence has been reviewed by Stiegler (1971) and Norris (1972a). In the case of voids it has been suggested that nucleation is possible at or on impurity atoms (both metallic and nonmetallic), depleted zones, gas bubbles, and also as a result of simple homogeneous nucleation. No single mechanism is able to explain all the experimental observations (Stiegler, 1971), although it is generally believed that mobile gas atoms play a critical role. In particular it is believed that the helium gas atoms produced as a result of $(n, \alpha)$ reactions play a critical role in both the nucleation and stabilization of voids. Almost no experimental attention has been paid to the equally important problem of the nucleation of interstitial dislocation loops. It is clear that in this latter situation it is also a question of a homcgeneous nucleation mechanism versus heterogeneous. nucleation mechanisms.

The theoretical aspects of nucleation have been considered in some detail and the reader is referred to the papers of Burton (1971), Katz and Wiedersich (1971; 
1973), and Russell (1971), for further details. The theoretical side must be further developed to include the following problems:

(1) Time-dependent nucleation theory of interstitial dislocation loops.

(2) Influence of diffusion gradients toward the embryos on nucleation rate.

(3) The effect of high-mobility divacancies on nucleation rate.

(4) Effect of stress on the nucleation rate, in particular of interstitial dislocation loops. The preferred nucleation of loops on certain crystallographic planes is important for the problem of radiation-induced creep.

(5) Heterogeneous nucleation of interstitial type loops.

A strong effort is also required on the experimental side to determine specific nucleation mechanism(s) on model systems under well-defined experimental conditions. This effort requires research on specimens which are well-defined initially from both a chemical and a microstructural point of view. The nucleation studies should concern both the voids and the interstitial dislocation loops. It is also worth noting that vacancy dislocation loops also provide a preferential sink for SIAs and that they may be of importance in the early portions of the nucleation process, but woulu disappear as a result of accumulating SIAs. The following experimental areas are of interest:

(1) The influence of specific impurities on the observed densities of voids and dislocation loops (both interstitial and vacancy) in a number of well-characterized pure metals and alloys. The refractory bcc metals are of particular interest.

(2) The effect of a known stress distribution on the observed density and crystallographic habit plane(s) of dislocation loops (both interstitial and vacancy).

(3) Measurements of the local concentration of impurity atoms (both metallic and nonmetallic) in voids and dislocation loops. The atom-probe field ion microscope (Müller et al., 1969, 1970; Brenner and McKinney, 1970; Brenner and Seidman, 1974) and the field desorption microscope (Panitz, 1973; 1974) should be very valuable in obtaining both qualitative and quantitative information on the local chemistry in the vicinity of these defects.

(4) The trapping of SIAs by impurity atoms. This is a very important area of research since it represents a possible mechanism for forcing all the vacancies to recombine with SIAs, and hence completely suppressing nucleation of interstitial dislocation loops and therefore voids.

\section{Growth problems}

The modeling of the growth of stable voids is an area in which a considerable effort has been expended in the past few years. The models have included both the socalled "mathematical models" which attempt to fit the observed swelling data to a number of arbitrarily chosen parameters contained in a mathematical function, as well as more fundamental physical models. The physical models are usually based on either diffusion-limited or surface-reaction-limited growth. The diffusion- limited growth model is mathematically more tractable than the surface-reaction-limited growth model and is based on the physical assumption that the void growth is limited solely by the rate at which vacancies are transported through the lattice to the void-lattice interface. Alternatively, the surface-reaction-limited growth model (Mansur et al., 1973) is based on the physical assumption that the void growth is limited by the ability of the voids to absorb vacancies at the voidlattice interface.

There is a reasonable body of experimental evidence, obtained from the annealing behavior of quenched and aged specimens (Balluffi and Seidman, 1971), which indicates that voids shrink by a diffusion-limited mechanism. Unfortunately, there is no experimental evidence to prove that void growth occurs by a diffusion-limited vacancy mechanism. On the contrary, one would expect an asymmetry between the shrinkage and growth of a void (Balluffi and Seidman, 1971) just as there is an asymmetry between the evaporation and growth behavior of a macroscopic crystal. In the growth behavior of a void, the void very quickly becomes faceted parallel to low-index crystallographic planes and at this point one would expect continued growth to become nucleation limited; i.e., limited by the rate at which the void-lattice interface can absorb vacancies. There is also the possibility that dynamic segregation (i.e. non-Gibbsian) effects could cause the growth of voids to become surface reaction limited.

The problem just described for the growth of voids also applies to the growth of the interstitial dislocation loops and the growth of the dislocation loops may also be a surface-reaction-limited problem and not a diffusionlimited one. The interstitial dislocation loop growth problem is a very important and neglected research area. It is essential to re-emphasize the fact that the interstitial dislocation loops provide the necessary biased sink for SIAs and hence are the primary cause of void growth. Very little quantitative information is available on the growth of interstitial dislocation loops and this is clearly an area in which further research is desirable.

The effect of dose-rate on the growth kinetics of both voids and interstitial dislocation loops is also a very important area of research. In order to understand the effectiveness of the electron and ion-irradiation experiments in simulating the neutron irradiation situation we must understand in detail the effect of dose-rate on growth kinetics. Some particular areas of research for future work are:

(1) Experimental studies of the growth kinetics of both voids and interstitial dislocation loops in irradiated materials. The experiments should be designed to distinguish between diffusion-limited and surface-reactionlimited growth. The diffuse $x$-ray scattering methods recently developed at both the Oak Ridge National Laboratory (Larson and Young, 1971) and KFA in Jülich, West Germany (Dederichs, 1970; 1971) could be particularly useful here. In addition, the field-ion microscope (FIM) could be useful if the void or interstitial dislocation loop number densities were above approxiimately $3 \times 10^{16} \mathrm{~cm}^{-3}$. 
(2) Experimental studies of the effects of radiationinduced dynamic segregation (Okamota et al., 1974; Okamota and Wiedersich, 1974) on the growth kinetics of both voids and interstitial dislocation loops. This problem could be studied employing electron microscopy, atom-probe field-ion microscopy and diffuse $\mathrm{x}-$ ray scattering techniques.

\section{Point defect-impurity atom interactions}

It is clear from the problems discussed so far that the interaction of impurity atoms with vacancies and SIAs plays an important role in both the nucleation and growth of voids and dislocation loops in irradiated materials. There is a strong and urgent need for experimental values of the Gibbs binding free energy $\left(g^{b}\right)$ between impurity atoms and both vacancies and SIAs in a wide variety of systems at elevated temperatures. The quantity $g^{b}$ is defined by the relationship

$$
g^{b}=h^{b}-T s^{b},
$$

where $h^{b}$ is the binding enthalpy, $s^{b}$ is the binding entropy, and $T$ is the temperature. This quantity has been measured only in a series of dilute aluminum alloys containing nontransition element impurities for the case of the vacancy-impurity atom Gibbs binding free energy.

The use of the length and lattice parameter change method (Simmons-Balluffi technique (Simmons and Balluffi, 1960; Beaman et al., 1964)) and the positron annihilation technique (Goland, 1971, Snead et al., 1972; Seeger, 1973) appear to be particularly promising approaches for the measurement of $g^{b}$ of vacancy-impurity atom pairs in fec alloy systems. The refractory bcc alloy systems are more difficult to study by means of the Simmons-Balluffi technique because of the very elevated temperatures at which the measurements must be performed and it is clear that some heroic efforts are needed to make further progress with this method. The positron annihilation technique appears to be a more promising one for the study of vacancy-impurity atom binding free energies in the refractory bcc alloys, and an expanded experimental effort in this area is required.

The determination of values of $g^{b}$ for impurity atomSIA pairs is almost nonexistent. Isochronal warming experiments on some irradiated fcc alloys and bcc alloys indicate strong effects of the concentration of impurity atoms in solid solution on the amount of recovery in a given temperature range, but values of $g^{b}$ have not been determined because of difficulties in interpreting the observed recovery spectrum in terms of exact mechanisms. The binding energies of larger clusters are also of importance. For example, detailed information on the binding energy of a SIA to a metal-gas atom cluster, and the binding energies of di-SIAs, tri-SIAs etc. is relevant to the void problem, and experimental and theoretical work in this area is urgently needed. The use of atomprobe field ion microscope techniques (Müller et al., 1969; 1970; Brenner and McKinney, 1970; Brenner and Seidman, 1974; Panitz, 1973; 1974; Seidman, 1973; Petroff and Seidman, 1973; Wilson and Seidman, 1973; Berger et al., 1973; Scanlan et al., 1971), and diffuse $x$-ray scattering methods in combination with detailed and quantitative electrical resistivity measurements appear to be promising tools for studying impurity atom-
SIA interactions.

\section{E. Saturation mechanisms}

Mechanisms which cause the voids to stop growing are referred to as saturation mechanisms. A number of possible saturation mechanisms have been suggested and discussed in detail in the review articles by Norris (1972a; 1972b) and Bullough and Nelson (1974). Some of these possible saturation mechanisms are as follows:

(1) Coherent precipitates serving as recombination centers for vacancies and SIAs.

(2) Coherent precipitates pinning dislocations and retarding them from climbing.

(3) The formation of a stable three dimensional void lattice.

(4) The lattice losing all its dislocations as a result of the climb and slip of dislocation loops into voids.

(5) The transformation of a void from a neutral sink into biased sink for SIAs as a result of an induced interaction between the elastic strain field of a dislocation and a void.

(6) Impurity atom trapping of all SIAs would result in copious recombination of the mobile vacancies with the SIAs.

(7) Preferential vacancy trapping at coherent precipitates in conjunction with pipe diffusion of vacancies along the dislocation lines connecting the coherent precipitates would result in the destruction of the excess SIAs arriving at the dislocation lines.

The problem of understanding saturation effects in detail is extremely important as it is the key to producing alloys which are resistant to swelling under LMFBR irradiation conditions. The recent discovery by Johnston and co-workers (Johnston et al., 1973a; 1973b, 1974) at the General Electric Laboratories in Schenectady, New York, that certain nickel rich alloys in a model $\mathrm{Fe}-\mathrm{Cr}-\mathrm{Ni}$ ternary system are almost completely resistant to swelling is ample proof that it is possible to control swelling. The exact mechanism or mechanisms which are responsible for this resistance to swelling have not yet been ascertained, but it is very possible that impurity atoms could play an important role via mechanism number 6 . Further detailed experiments on additional bcc and fcc model alloy systems are required. These experiments should be performed on specimens which are very well characterized both chemically and microstructurally. This point is strongly emphasized since it is clear that the possible saturation mechanisms listed above involve complex interactions between the chemistry and microstructure of the specimen. Conventional electron microscopy, high-voltage electron microscopy, field ion microscopy and atom-probe field ion microscopy appear to be useful tools for studying this problem.

\section{F. Specific recommendations}

(1) Further detailed experimental and theoretical studies to elucidate the mechanisms responsible for the nucleation and growth of voids in model fcc and bcc alloy systems with well-characterized specimens from both a chemical and a microstructural point-of-view. New and innovative experiments regarding the nucleation problem 
are very much needed.

(2) Experimental studies on model fcc and bcc alloy systems to try to elucidate the mechanisms responsible for the saturation of void growth. The experiments should, once again, be performed on specimens well characterized chemically and microstructurally. 


\section{THEORY OF DAMAGE PRODUCTION}

Radiation damage theory encompasses a broad class of problems, ranging from the dynamics of displaced atom production through the kinetics of point defect migration and agglomeration to the effects of the final defect configurations on the physical properties of an irradiated solid. While there is at least partial theoretical understanding of many of these problems, further work in several areas appears to be important to the development of the nuclear energy technology. The most critical need certainly arises from the increasing use of heavy ion irradiation to simulate the effects of fast neutrons, a procedure which rests on still uncertain descriptions of displacement cascade production. Further study is needed of the processes whereby dislocation loops and voids are nucleated, especially of the role played therein by foreign atoms, whether present as impurities in the solid or introduced as transmutation products during irradiation. Improvements in theoretical understanding of the effects of radiation produced defects on the mechanical properties of solids would be very welcome, especially in the areas of creep, fracture, and ductility changes. In the following paragraphs, the current status of radiation damage theory will be summarized briefly and some places indicated where further work is needed. ${ }^{7}$ It seems likely that most of this research could be carried out in universities, although it must be emphasized that close interaction between theorists and experimentalists will be necessary. Thus, the university theorist will find it helpful or even essential to maintain close contacts with experimentalists, not only in his own department, but also in the large nuclear energy research and development laboratories.

The production of radiation damage commences with the ejection of an atom, the primary recoil, from its lattice site by interaction with an incident neutron, ion, or electron. Theoretical estimates of the energy spectra of the primary recoils produced by various incident radiations require differential cross section data for the many possible processes. In power reactors, elastic and inelastic scattering of fast neutrons, $(n, 2 n)$ reactions, and various charged particle production reactions are the most significant. In general, the necessary data are available although some gaps exist. When reactor damage is simulated by ion irradiations, the incident ion itself is conveniently regarded as the primary particle. The initial kinetic energy of the primary is dissipated in part in electron excitation and in part in quasielastic atomic collisions, some of which lead to additional displaced atoms. Calculation of the portion of the initial

${ }^{7}$ General reviews of radiation damage production theory include:

(a) G. Leibfried, 1965, Bestrahlungseffekte in Festkörpern (Teubner, Stuttgart).

(b) M. W. Thompson, 1969, Defects and Radiation Damage in Metals (Cambridge University Press, Cambridge).

(c) P. Sigmund, 1972, Revue Roum. Phys. 17, 823, 969, 1079.

(d) M. T. Robinson, 1972, in Radiation Induced Voids in Metals, edited by J. W. Corbett and L. C. Ianniello (U.S.A.E.C., CONF-710601), p. 397. primary energy which appears as electron excitation is an important theoretical problem. Its solution is essential in establishing the basis of the ion simulation technique for accelerated materials testing. There is ample experimental evidence (Brown and Moak, 1972; Northcliffe and Schilling, 1970; Cheshire and Poate, 1970) that the widely used LSS theory (Lindhard, Scharff, and Schiøtt, 1963) of the electronic stopping cross sections of moderate energy ions does not correctly predict the dependence of these cross sections on the projectile velocity, mass, and charge nor on the mass and charge of the target atoms. An improved solution to this challenging problem is urgently needed.

After about $10^{-12} \mathrm{sec}$, the energies of the displaced atoms reach the thermal range. This nascent damage state consists of a number of displaced atoms, an equal number of vacant lattice sites, and (in polyatomic systems) some amount of chemical disorder. In metals, the nascent damage state is produced entirely by the atomic collisions, but in insulators and possibly in semiconductors, electron excitation also can lead to damage. The structure of the nascent cascade is determined by the primary recoil energy and in turn determines the subsequent development of the damage. This structure is still very poorly understood, especially for the most important case of fast neutron irradiation. Particular problems concern the occurrence of defect clusters in the nascent cascade and the role of long range replacement sequences in transporting the interstitials far from the vacancies. Studies of the conditions under which stable Frenkel pairs are produced in dense cascades are needed. Does the concept of a displacement threshold energy remain valid in such dense cascades? That part of the primary energy which is not expended in electron excitation is termed the damage energy. In comparisons of ion and neutron damage, it is usual to assume that the number of nascent displacements in metals is proportional to the damage energy, but this assumption may be incorrect for the dense cascades produced by fast neutrons (Beeler, 1966; Robinson and Torrens, 1974). It is observed (EerNisse, 1971) that the stress induced into irradiated materials is less for light incident ions than for heavy ones for the same density of total damage energy. Is this effect related to the more dense collision cascades induced by the heavier ions, or is it evidence of different effective displacement thresholds for heavy and light ions? The interaction of deposited damage with local electronic excitation may also play a role in the effectiveness of damage production by the various charged particle irradiations. A satisfactory solution to these problems is needed to allow meaningful comparisons of ion, electron, and fast neutron irradiations to be made.

The defects produced in the nascent cascade are generally mobile at the temperatures of interest in power reactors. A large fraction of them will annihilate; the balance will either produce new agglomerates, add themselves to existing agglomerates from previous cascades, or interact with impurities and extended defects in the irradiated solid. Theoretical understanding of these processes is needed. The most important topic 
seems to be the nucleation of dislocation loops and of voids. The possible role of clusters produced directly in the nascent cascade needs study. Impurities initially present in the target, dislocation structures, and transmutation products may alter the cascade structure or influence agglomerate nucleation in other ways.

The influence of the final defect configurations on the technologically important properties of the irradiated solid require careful study. The most important area for fast fission reactors, and perhaps for CTR devices, appears to be the influence of irradiation on high temperature creep: very little useful theoretical work seems to be available. While it is unlikely that an accurate predictive theory could be developed to reduce significantly the need for pressure vessel surveillance, studies are needed of the effects of irradiation produced defect structures on ductility and on fracture mechanics, in systems of power reactor interest.

Additional work is also needed on the effects of radiation damage at material interfaces, particularly bonding interfaces and electrical and thermal contacts. In the vicinity of these interfaces radiation damage will not only produce defect clusters, but will also lead to transport of the dissimilar atomic species across the common boundaries, both through enhanced diffusion and through recoil of atoms from collisions with the primary radiations. Further understanding of the role these effects might have on the degradation of the interface properties is needed to allow meaningful design choices of material's to be used in such applications.

Many other interesting problems have been omitted in the previous paragraphs, a few of which should be mentioned because of their possible technical importance. The introduction of damage into insulators and semiconductors by the electronic excitation component of the primary recoil energy needs further study. Experiment shows a damage component in some insulators (EerNisse and Norris, 1974) and semiconductors (Pabst and Palmer, 1974) which is directly proportional to the average energy deposited into electronic excitation (Brice, 1970; 1973) by ion bombardment. In order to determine the details of the damage mechanism, which are not known, study of the individual excitations may be necessary. In addition, the enhanced annealing and diffusion of defects and impurities observed in these materials, may also be related to the deposition of energy into electronic excitation since the kinetic properties of these centers are often strongly charge state dependent. (See Secs. IX and $\mathrm{X}$.) The striking nature of the void lattice (Evans et al., 1972) also calls for study, especially of the mechanism of binding and of the possible significance that this may have for other areas of defect physics. 


\section{SIMULATION OF REACTOR NEUTRON DAMAGE}

\section{A. Introduction}

The use of energetic ions and electrons to simulate the effects on materials of the massive neutron fluences expected in the design life of current and next generation reactors arose from the unavailability of sources of neutrons of sufficient intensity to carry out meaningful tests in reasonable lengths of time. Simulation began at Harwell in 1969 with the use of $100 \mathrm{keV} \mathrm{H}, \mathrm{C}, \mathrm{O}$, and Fe ions (Nelson et al., 1970) as an imaginative approach to estimating materials swelling in first-generation Liquid Metal Fast Breeder Reactors (LMFBR). Ion simulation now makes principal use of nickel ions in the 3-50 MeV range, and protons and deuterons of 1-10 MeV. To these have been added simulation by electrons of $0.6-1.0 \mathrm{MeV}$ as are available at high current densities in high voltage electron microscopes (HVEM). The attempt in all cases is to provide a means of creating defects in solids at very high rates. Figure 1 compares ion and neutron atomic displacement rates for particles of major interest. Simulation studies have been extremely fruitful and have led to relatively rapid assays of void produced swelling in materials of potential reactor interest. ${ }^{8}$ Recommended procedures for carrying out simulation are shortly to be issued as an American Society for Testing and Materials report (ASTM, 1974).

A summary of the advantages and disadvantages of simulation as initially perceived are listed in Table IV. The advantages A.2 and A. 3 and disadvantage D. 5 are related to the importance of impurities in the nucleation and growth of voids and other defect microstructures. This is discussed further in connection with Table V. For a more detailed discussion of these effects see Sec. IV-Voids and Dislocations. Disadvantage D. 1 refers to the problems of studies of creep and reduced ductility in the very shallow layers affected by the simulating ions. D. 3 has to do with the necessity of raising the temperature in a simulation experiment with respect to the temperature in a reactor in order to increase the diffusion rates of defects and hence try to keep the defect reaction rates in scale with the higher production rate.

The simulation of reactor neutron damage effects us-

\footnotetext{
${ }^{8}$ Recent reviews of the field are available in the following references:

(a) G. L. Kulcinski, Applications of Ion Beams to Solids, edited by S. T. Picraux, E. P. EerNisse and F. L. Vook (Plenum Press, N. Y., 1974), p. 613.

(b) Properties of Reactor Structural Alloys after Neutron or Particle Irradiation, Proceedings of the Seventh International Symposium on Effects of Radiation on Structural Materials, Gatlinberg, Tennessee, June 11-13, ASTM, 1975, to be published.

(c) Effects of Radiation on Substructure and Mechanical Properties of Metals and Alloys, ASTM STP 529, 1973.

(d) Radiation Induced Voids in Metals, edited by J. W. Corbett and L. C. Ianniello, AEC Symposium Series 26, CONF701601 (1972).

(e) Voids Formed by Irradiation of Reactor Materials, edited by Pugh et al., BNES (1971).
}

ing accelerator produced neutrons is an alternative to the use of ions or electrons. The neutron spectra from sources such as $(d, n)$ reactions or from the beam dump in LAMPF are in general different from the spectra of fission and fusion reactors. This leads to different energy distributions for the primary knock-on atoms in a material. However, the major difference in simulation arises from the different rates at which nuclear reactions produce impurities-gas or otherwisethat may shift the balance in the subsequent defect reaction rates. It should be noted that reaching interesting neutron flux levels in this way is relatively expensive and the flexibility of radiation geometry is rather constrained. Major new facilities for this type of simulation using either $14 \mathrm{MeV}$ or other fast neutrons are under consideration.

Transmission electron microscopy (TEM) has provided the most valuable tool for defect studies in simulation although the measurement of the height of the surface step produced in an ion bombarded region has been used to good advantage in rapid assays of the temperature dependence of material swelling. TEM permits microscopic evaluation of the structure of the defects formed-dislocation loops, precipitates, voids, etc. An example is shown in Fig. 2. This work is tedious because of the necessity of thinning each sample to a few thousand angstroms or less for microscopic examination. Nevertheless it is extremely revealing of the sensitive balance of defect reaction processes that take

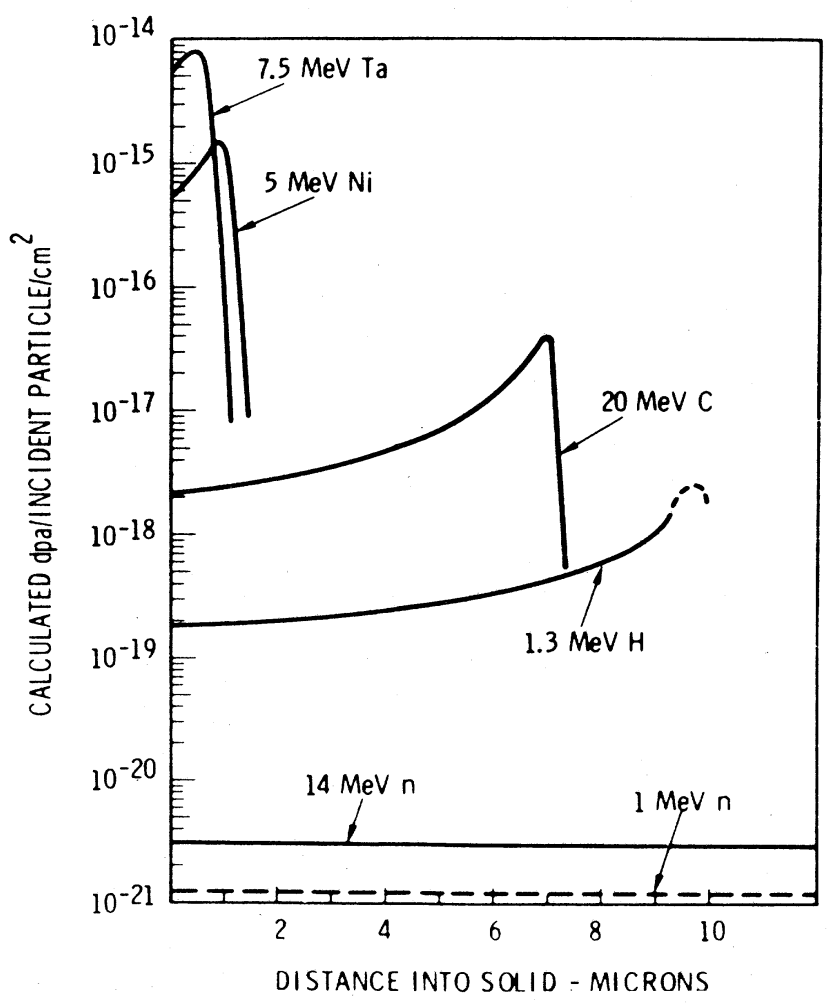

FIG. 1. Displacement effectiveness for various energetic particles in nickel. 
TABLE IV. Assessment of neutron damage simulation with charged particles.

\begin{tabular}{|c|c|c|c|}
\hline \multicolumn{2}{|r|}{ Advantages of simulation } & \multicolumn{2}{|r|}{ Disadvantages of simulation } \\
\hline A.1 & Acceleration of damage rates by $10^{5}-10^{6}$ & D. 1 & $\begin{array}{l}\text { Short particle ranges produce } \\
\text { damage not well suited to study } \\
\text { of mechanical properties }\end{array}$ \\
\hline A. 2 & Allows selective impurity doping & D.2 & Nonuniform damage \\
\hline A. 3 & $\begin{array}{l}\text { Allows separation of atomic displacement } \\
\text { and gas atom effects }\end{array}$ & D.3 & $\begin{array}{l}\text { Temperature shift required to } \\
\text { scale swelling rates }\end{array}$ \\
\hline A.4 & Non-radioactive samples & D.4 & $\begin{array}{l}\text { Different primary knock-on } \\
\text { atom energy distributions, } \\
\text { particularly for HVEM }\end{array}$ \\
\hline A. 5 & $\begin{array}{l}\text { HVEM can examine defect structures } \\
\text { as they develop }\end{array}$ & D.5 & $\begin{array}{l}\text { Precipitation not necessarily } \\
\text { simulated }\end{array}$ \\
\hline A. 6 & Low cost & & \\
\hline A.7 & $\begin{array}{l}\text { Rapid screening tool for new alloy } \\
\text { development }\end{array}$ & & \\
\hline
\end{tabular}

place. In some cases electron microscopes have been coupled with ion accelerators to permit dynamic observations of defect processes. Microscopes in the $100 \mathrm{kV}$ range are useful here but the thinness of samples required makes the proximity of surfaces as defect sinks a significant problem. High voltage electron microscopy allows thick samples to be used, thick enough that surface sinks for defects are of less importance. It also permits studies of defect structure changes to be made dynamically since the high energy electrons themselves produce atomic displacements.

It would be valuable if other techniques of defect analysis as well as techniques for studying the mechanical property damage could be devised to complement the microscopic defect observations for simulation studies. $\mathrm{X}$-ray scattering might be useful in this way. Higher energy ion beams would make some of these problems easier by extending the damage further into the bulk of the material. However, this reasoning cannot be carried too far, e.g., it would be extremely difficult to produce a high enough energy self-ion $(Z>10)$ that would pass completely through a specimen suitable for mechanical property measurements $(\sim 100 \mu \mathrm{m})$. For example the range of $100 \mathrm{MeV} \mathrm{Al}$ ion in $\mathrm{Al}$ is $\sim 20 \mu \mathrm{m}$.

\section{B. Status of technology}

\section{Charged particle simulation}

After the first initial successes in this field, more detailed studies of ion simulation techniques have revealed some critical physics related problems that need to be thoroughly examined. Some of the more important are listed in Table $\mathrm{V}$, and discussed below.

Due to the limited range of high energy particles and the thickness limit for transparency in HVEM, one must be extremely careful about the interaction between the damage zone and the surface of the samples. It is generally known that the thickness of denuded zones from free surfaces increases with increasing temperature. However, the exact extent of this denuded zone cannot be predicted with any accuracy from first principles. More information on defect diffusion and agglomeration during high rate damage processes is required.

Another difference between ion simulation and neutron damage is the primary knock-on atom (PKA) spectrum. Whereas the average PKA energy for fission neutrons is $\sim 20 \mathrm{keV}$, it is only $\sim 2 \mathrm{keV}$ for heavy ions, and $\sim 100$ $\mathrm{eV}$ for $1 \mathrm{MeV}$ electrons. Processes which are sensitive to the size of the displacement cascade from a single

TABLE V. Physics related questions for neutron damage simulation techniques.

\begin{tabular}{lll}
\hline \hline \multicolumn{1}{c}{ Phenomena } & Heavy ion & HVEM \\
\hline $\begin{array}{l}\text { Influence of surface proximity } \\
\text { on damage state }\end{array}$ & Requires $E_{\text {ion }} \geq 1 \mathrm{MeV}$ & $\begin{array}{c}\text { Requires sample thickness } \\
\leq 1 \mu \mathrm{m}\end{array}$ \\
PKA spectrum & $E_{\mathrm{ave}}^{\text {neutron }} / E_{\mathrm{ave}}^{\text {ion }} \sim 10$ & $\begin{array}{c}\text { Single atom displacement } \\
E_{\mathrm{ave}}^{\text {elec }} \sim 100 \mathrm{eV}\end{array}$ \\
Spatial distribution of damage & $\begin{array}{c}\text { High density along track; } \\
\text { beam sweeping effects }\end{array}$ & $\begin{array}{c}\text { Homeneous } \\
\text { Romlinear scaling of diffusion and reaction rates of } \\
\text { point defects }\end{array}$ \\
Transmutation effects & $\begin{array}{c}\text { Requires pre- or simultaneous injection } \\
\text { Constraint of damage zone by undamaged materia1 }\end{array}$ \\
\hline \hline
\end{tabular}




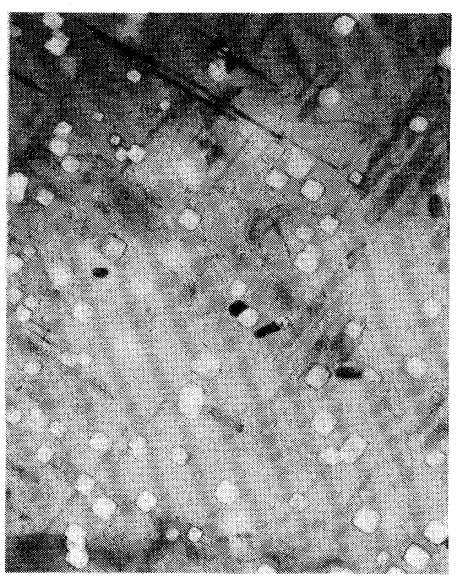

$700^{\circ} \mathrm{C}$

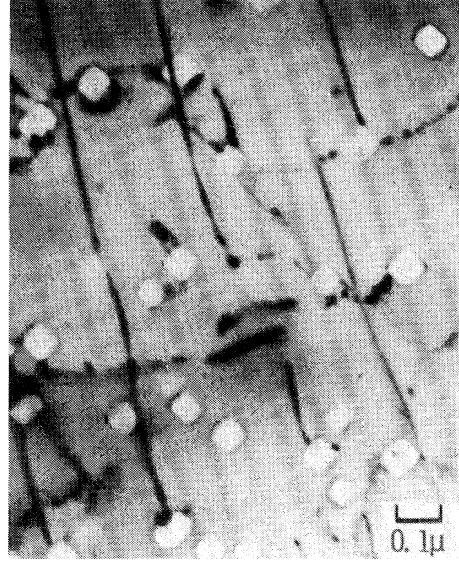

$800^{\circ} \mathrm{C}$
FIG. 2. Voids in vanadium after 7.5 MeV Ta bombardment to $\sim 30 \mathrm{dpa}$. primary knock-on, such as the formation or re-solution of precipitates in alloys, will not be accurately simulated by HVEM and may be altered by the smaller displacement spikes of heavy ion irradiation. The use of protons for simulation must be critically examined in this regard.

There are also spatial variations in the production of damage with the various types of bombarding particles. Both neutron and electron damage cascades are homogeneously distributed, whereas there is a high density of cascades along the path of a high energy heavy ion. We need to understand how these high microscopic damage densities will alter solid state processes such as the nucleation and growth of voids and dislocation loops.

Another question which has recently been raised is the effect of beam sweeping versus beam defocussing to insure uniform irradiation of a specimen. The question here goes deeper than just that of an experimental technique; it has to do with the production of damage in short, high density bursts with relatively long annealing times between the bursts. Experiments are required not only to assess the validity of such a technique, but also to see how it might apply to real irradiation conditions in pulsed nuclear systems such as theta pinch and laser fusion reactors (see Sec. II A).

Another critical area, and one which lies at the very heart of the simulation technique, is the nonlinear scaling of diffusion and reaction rates of point defects. At very high displacement rates the amount of recombination is greatly enhanced. This has the effect of reducing the supersaturation levels below what one might expect by simply scaling the defect production rates. Rate theories and defect trapping efficiencies must be developed to adequately describe this situation before the technique will be accepted by those in charge of engineering design considerations.

The fact that the ion simulation techniques do not produce transmutation reactions is both an advantage and a disadvantage. The disadvantage is that since impurities, especially gas atoms, are known to have drastic effects on the formation of microstructural defects, one is never sure that the relatively 'clean' charged particle bombardments duplicate the in-reactor response. The dop- ing of gas atoms has, up to now, been accomplished by preinjection of an unirradiated specimen with the amount of gas that would be accumulated over the irradiated lifetime of the specimen. However, such large initial concentrations of gas may completely bias the formation of certain microstructural defects which would not be formed if the impurity were added monotonically with the damage. The sensitivity of cluster defect production to the manner in which the impurities are added must be understood and experimental methods of adding these impurities along with the point defect damage must be devised.

A final question on simulation studies has to do with the stress state imposed on the damage region in thin foils during irradiation. This effect is considerably different for HVEM studies where the 'cylindrical' damage region in the foil, bounded by denuded regions on the top and bottom and undamaged crystal around the circumference, may be subjected to considerable compressive stresses during irradiation. This effect is particularly dramatic for high swelling values $(\sim 10 \%)$. The damage zone in the heavy ion bombarded material is always subjected to the stresses imposed by the undamaged region beyond the range of the bombarding particle as well as the undamaged surface around the beam. Analysis of this state of stress, and the effect of such stress on the formation and growth of microstructural defects is absolutely essential if meaningful simulation work is to be accomplished.

\section{Simulation with neutron sources}

In the previous section, critical problems associated with the interpretation of charged-particle simulation of neutron damage have been outlined. From that discus sion it is evident that there are at least five reasons why neutron irradiation experiments must be carried out:

(i) To determine the validity of ion simulation, comparison with neutron damage is necessary.

(ii) Ions usually simulate displacements per atom but not the recoil spectra or damage cluster size generated by neutrons.

(iii) Neutrons create the gaseous impurities, $\mathrm{H}$ and $\mathrm{He}$, homogeneously throughout the volume of a relatively large specimen during irradiation. 
(iv) Neutrons produce nongaseous transmutation products which can alter physical properties of alloys. Impurity concentrations are, thus, time dependent during an irradiation.

(v) The study of runaway swelling in such solids as $\mathrm{SiC}$ and graphite requires an intense neutron source.

Information concerning neutron damage in breeder and fusion reactors is needed. In the breeder-reactor program, EBR2 is the primary source of neutrons; and it will be joined by the Fast Flux Test Facility (FFTF) some time in the future. However, present additional sources are needed to accommodate the large number of experiments that are being planned.

For the foreseeable future there will be no fusion reactor available for studies of radiation effects produced by this new neutron spectrum. Thus, existing or proposed neutron sources will have to be used. Several low-intensity $14 \mathrm{MeV}$ neutron sources already are in use, others have been proposed. The beam dump at LAMPF will soon be available as a source, and a number of cyclotrons are expected to be used as deuteron sources for inducing the $(d, n)$ reaction on suitable targets. In all cases, the neutron spectrum is not that expected at the first wall of a typical fusion reactor. Therefore, even when neutrons are being used directly in an experiment, the question of simulation remains. To answer this question it will be necessary to conduct experiments at a variety of neutron sources, and to relate the results to the differences between spectra. It should then be possible to predict the results for a hypothetical fusion spectrum. Such a program has a number of research components:

(i) Good dosimetry techniques must be developed to ensure accurate knowledge of each neutron source spectrum.

(ii) High-energy neutron cross section data will be needed for use in conjunction with those sources which produce neutron energies greater than $14 \mathrm{MeV}$.

(iii) Models which relate energy losses in a solid to damage production will have to be developed further.

(iv) Techniques for the production of intense neutron fluxes must be investigated so that eventually high-fluence experiments can be conducted.

\section{Recommendations}

(1) Establish the range of validity (i.e., energy, displacement level, displacement rate, $T$, etc.) of ion and electron simulation techniques in providing an accurate means for anticipating fission and fusion neutron damage effects.

(2) Devise techniques for simulation studies of changes in mechanical properties such as creep and embrittlement with and without externally applied stress. In addition to providing data more quickly, such simulation could provide information on stress enhanced effects.

(3) Develop a wider range of ion beam facilities for simulation studies. These should include higher beam currents, a wider variety of ions and clean target systems in which accelerator contamination of refractory metal targets at high temperature can be avoided.

(4) Assess the need for simultaneous gas atom injection and ion beam irradiation as contrasted with preinjection.

(5) Establish the theoretical relationship between 'free' defect concentrations (those defects surviving initial cascade recombination) associated with electron, proton, heavy ion, fission and fusion neutron bombardment (see Sec. V on Theory of Damage Production).

(6) Develop techniques for performing simulation experiments using neutron sources. 


\section{HYDROGEN AND HELIUM IN METALS}

\section{A. Hydrogen in metals}

Hydrogen-related effects on materials in radiation environments are important in present reactor systems and will be increasingly significant in the proposed fast breeder and fusion systems (see Sec. II and AEC/WASH 1240-73, 1973, and AEC/WASH 1206, 1972). The major anticipated problems are listed in Table VI.

Hydrogen embrittlement is presently recognized as a problem at temperatures near $300^{\circ} \mathrm{K}$ in those systems which form stable hydrides (Birnbaum et al., 1974) (Group Vb, Zr, Ti, etc.) and in ferritic steels (H. Johnson, 1969). Austenitic stainless steels and nickel base alloys are known to be subject to embrittlement under certain conditions, but the magnitude of the problem in these alloys has not been well defined. Group VIb metals such as Mo, are believed to be "immune" to hydrogen embrittlement, a belief based on little experimental foundation. In all of these systems the effects of hydrogen on the high temperature ductility is not known. The mechanism of low temperature hydrogen embrittlement in "hydride forming" systems has been shown to be associated with cleavage of stress-induced hydrides. In the "non-hydride" forming systems the embrittlement mechanism has not been established.

The understanding of hydrogen embrittlement would be advanced by studies of:

(a) hydrogen embrittlement in refractory metal alloys and stainless steels above room temperature; particularly under conditions where lattice defects are being simultaneously generated by irradiation,

(b) hydrogen solute effects on phase equilibria,

(c) precipitation mechanisms in stress fields,

(d) the energy to form a crack in the absence of plastic deformation (i.e., the "cohesive energy") and the effects of hydrogen thereon. Of particular interest is the value of the maximum force required to break an atomic bond in the presence of hydrogen,

(e) the thermodynamics and kinetics of high temperature gas bubble formation $\left(\mathrm{H}_{2}, \mathrm{CH}_{4}, \mathrm{H}_{2} \mathrm{O}\right.$, etc.) involving hydrogen reactions with other interstitial solutes.

An estimation of the concentration of hydrogen isotopes in various reactor components requires a knowledge of hydrogen isotope production rates, diffusivities and permeabilities (Birnbaum and Wert, 1972). The latter two parameters are poorly known in most bcc systems, particularly at elevated temperatures. It has been shown that the diffusivity and permeability are sensitive to interstitial solutes, precipitates, surface phases and other lattice defects. Hydrogen diffusion in the bcc metals is nonclassical; anomalously large isotope effects and non-Arrhenius tunneling behavior at low temperatures have been observed. The mobility of solute hydrogen in both the bcc and fcc metals is extremely high $\left(D \approx 10^{-5} \mathrm{~cm}^{2} / \mathrm{sec}\right.$ at $300^{\circ} \mathrm{K}$ in the Group Vb metals). In addition to volume diffusion, permeation requires the transport of hydrogen across surfaces; a process which is poorly understood.

Further work on hydrogen diffusion and permeation should include:

(a) high temperature diffusivity and permeability studies,

(b) an extension of the theoretical understanding to include isotope effects (Stoneham, 1972),

(c) studies of the mechanism of hydrogen transport across surfaces,

(d) an examination of stress effects on diffusion and solubility,

(e) investigations of local phonon modes and the local electronic structure near the hydrogen,

(f) studies of hydrogen diffusion in a radiation environment and of the interaction of hydrogen with radiationinduced defects.

Since the properties of bcc metals are particularly dependent on interstitial impurities, attention should be given to the thermodynamics of gas-metal systems, ${ }^{9}$ and to the problem of gas formation by nuclear reactions. In particular, careful studies of neutron cross sections for both direct $(n, p)$ and $(n, d)$ reactions and for indirect reactions which involve transmutation products should be carried out.

The relatively high hydrogen concentrations expected in reactor components coupled with the high diffusivities suggest that the role of hydrogen in void nucleation and gas bubble formation be carefully examined, particularly in those systems having low hydrogen solubility. A number of synergistic alloy effects such as internal hydriding of alloying elements and transmutation products must also be considered.

As a basis for solution of the above problems, improvements in understanding the fundamental properties of hydrogen in crystal lattices are required. Calculations of the effect of hydrogen on the electronic band structure by the Augmented Plane Wave (APW) method have been carried out (Switendick, 1972) and need to be extended, partic ularly to low hydrogen concentrations. Another theoretical approach to understanding the effect of hydrogen on the surface of metals is the SCF $-X-\alpha$ scattered wave calculations (K. Johnson, 1973), and these should lead to understanding the mechanism of hydrogen transport across surfaces. The method also appears applicable to calculations of hydrogen effects on surface energies (i.e., on the "cohesive energy") and to calculation of the crystal site location of hydrogen. Experiments designed to test these theories, such as experiments on the hydrides and field ion microscopy to determine the state of hydrogen on surfaces, should be extended. Ion channeling studies (Picraux and Vook, 1974) appear to be a promising method of determining both the site at which hydrogen is located and the interactions of hydrogen with specific trapping defects.

Some of the most promising areas of research on hydrogen effects in solids not previously discussed are:

\footnotetext{
${ }^{9}$ See articles by T. B. Flanagan, and W. A. Oates, 1972, Ber. Bunsenges. Phys. Chem. 76, 706; B. Baronowski, 1972, Ber. Bunsenges. Phys. Chem. 76, 714; and H. Brodowsky, 1972, Ber. Bunsenges. Phys. Chem. 76, 740.
} 
TABLE VI. Hydrogen-related technological problems.

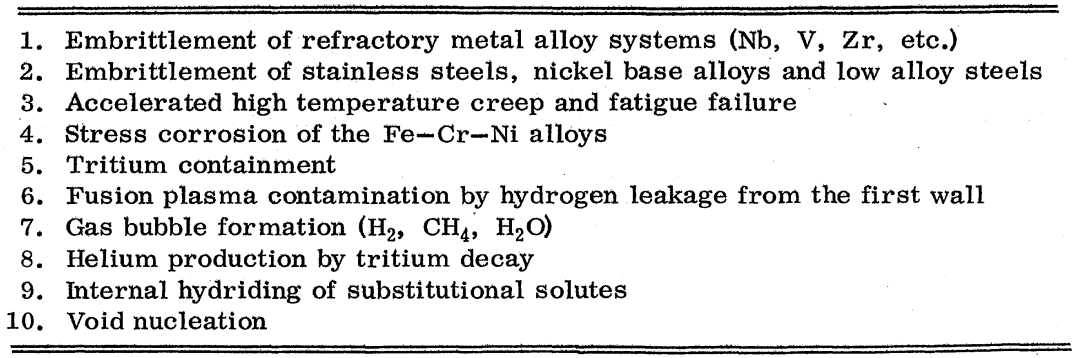

(a) in situ electron microscope studies of processes occurring at crack tips in metal-hydrogen systems,

(b) electron microscope studies of hydride precipitation,

(c) anelastic studies (high frequency and Gorsky ef fect) (Völkl, 1972) of hydrogen diffusion and of the interaction of hydrogen with lattice defects produced by irradiation,

(d) studies of the phonon modes associated with hydrogen and of the critical phenomena (Alefeld, 1972) in systems such as $\mathrm{Nb}-\mathrm{H}, \mathrm{V}-\mathrm{H}$, etc., using techniques such as neutron scattering (Gissler, 1972) and Raman spectroscopy,

(e) ion channeling and scattering experiments to determine the site location and interaction of hydrogen with specific types of traps,

(f) theoretical studies of the electronic structure of dilute metal-hydrogen systems,

(g) theoretical studies of the interaction of hydrogen with surfaces,

(h) studies of the interaction of hydrogen with surfaces using selective techniques such as the atom probe and the field desorption microscope.

\section{B. Helium in metals}

Anticipated helium production rates in the LMFBR and the CTR suggest that helium-induced intergranular fracture with corresponding loss of ductility may be a serious problem at elevated temperatures. Helium also has been postulated as contributing to the stabilization of radiation-induced voids during nucleation. The behavior of helium in metals has been examined, using (Blackburn, 1966): (a) theoretical and experimental studies of properties on an atomic scale such as solubility, diffusivity, trapping, site location, and (b) bulk property measurements of samples charged with helium by irradiation techniques. The processes by which helium agglomerates into bubbles, migrates to grain boundaries, and induces fracture have not been studied in detail.

Some calculations of helium configuration, diffusivity, and trapping have been carried out using interatomic potentials developed for various bcc and fcc metals (Wilson, 1973). The experimental verification of the formation, migration, and binding energies thus calculated is lacking, primarily because the usual techniques for measuring these values are not applicable for inert gases with very low solubility. The techniques required to introduce helium into metals normally involve ion implantation or $(n, \alpha)$ transmutations of solutes. These methods also introduce defect trapping sites. Once introduced in- to the metal, helium is amenable to study by many of the techniques of solid state physics, although few such experiments have been carried out. Recently, thermal desorbtion spectra studies (Kornelsen, 1972) and ion channeling experiments (Picraux and Vook, 1974) have examined the trapping, mobility and site location of He and have shown reasonable agreement with the theoretical calculations. Theory and experiment both indicate a strong interaction between $\mathrm{He}$ and radiation-induced defects.

Helium embrittlement has been studied by elevated temperature creep rupture or tensile testing subsequent to helium charging by neutron or $\alpha$-particle irradiation. The embrittlement occurs only at temperatures where substantial migration of $\mathrm{He}$ is possible, i.e., above a threshold temperature of the order of half the melting temperature. Although strength parameters at these temperatures are not affected by helium, premature intergranular fracture causes a reduction in ductility. A qualitative model of $\mathrm{He}$ bubble formation and migration to grain boundaries (a process strongly affected by stress or temperature gradients) has been postulated on the basis of a few electron microscopy and fractography studies. Little information is available regarding microstructural influences on this process. The effects of simultaneous helium and defect production by irradiation have not been studied, although the strong interaction of He with traps suggests that such studies are necessary.

In view of the limited understanding the opportunities for promising research in helium embrittlement are numerous as indicated in the following examples:

(1) Helium production rates under anticipated reactor conditions must be determined taking into account energy dependent cross sections and $(n, \alpha)$ reactions involving prior transmutation products, e.g., ${ }^{58} \mathrm{Ni}(n, \gamma){ }^{59} \mathrm{Ni}$ followed by ${ }^{59} \mathrm{Ni}(n, \alpha)^{56} \mathrm{Fe}$.

(2) The solubility, diffusivity and trapping parameters of helium in metals must be determined, along with the kinetics of bubble formation and migration.

(3) The role of microstructure and lattice defects (such as dislocations and vacancies) in the formation and $\mathrm{mi}-$ gration of helium bubbles must be determined. Embrittlement under simultaneous irradiation and helium production conditions should be studied.

(4) Simplified methods of helium charging to simulate reactor conditions should be developed. These may possibly be based on alpha particle irradiation or on the decay of tritium to ${ }^{3} \mathrm{He}$. In the latter case, access to $\mathrm{Na}-$ tional Laboratory facilities seems essential. 


\section{Specific recommendations}

(1) An understanding of the effects of hydrogen on the mechanical properties of alloy systems should be developed. The effects of both solute hydrogen and hydrogen atmospheres must be considered.

(2) The behavior of helium in solids and its effects on the mechanical properties should be established using both theoretical and experimental methods. Interactions of helium with other defects must be understood. 


\section{INTERACTION OF SURFACES AND RADIATION}

\section{A. The problems}

The interaction of radiation with a solid surface can be looked at from two points of view: as changes that occur in the particle or photon distributions outside the surface or as changes in the material of the surface itself. There is little evidence that either of these is important in fission reactors, but both will be of major significance in fusion systems. The remarks to follow will thus focus on surfaces that are interfaces to the vacuum of a CTR. Such a surface is shown schematically in Fig. 3.

Processes important to the plasma include:

(1) the reflection of particles (and energy) back into the plasma;

(2) charge exchange of plasma particles at the wall;

(3) secondary electron and photon production; as well as contamination of the plasma by:

(4) desorption of adsorbed species;

(5) sputtering of wall material;

(6) blister formation and exfoliation of the wall.

Processes (5) and (6) are important to the wall because they produce erosion. In addition the wall is sensitive to mechanical creep and ductility changes due to:

(7) defects and foreign atoms introduced into the wall.

At this early stage in CTR development, the more critical problems concern the plasma since energy and particle losses must be minimized in order to achieve successful heating of magnetically confined plasmas. When fusion reactors (magnetically confined or otherwise) are producing useful levels of power, the problems of wall property degradation will become critical. Study in both areas is important at this time. It must be emphasized that surface effects in CTR devices are strongly influenced by impurities, by adsorbed surface films, and by surface topography. Scrupulous attention must be paid to these points in all investigations in this area. The following paragraphs indicate briefly the current status of research on this almost bewildering array of phenomena and some promising areas of future research. ${ }^{10}$

In present magnetic confinement devices such as the tokamak machine, ORMAK, the walls are irradiated with neutral hydrogen atoms produced by charge exchange reactions in the plasma. Particles in the energy range below about $500 \mathrm{eV}$ are currently the most important, although higher energies will be reached as plasma heating becomes more effective. The energies of $\mathrm{He}$ particles escaping from a thermonuclear plasma will range up to about 3.5 MeV depending on detailed plasma properties. An important question is the so-called recycling of these particles, that is, their reflection back into the plasma with reduced energies. Experimental measure-

\footnotetext{
${ }^{10}$ Detailed discussion of many aspects of CTR surface physics problems will be found in the "Proceedings of the Conference on Surface Effects in Controlled Thermonuclear Fusion Devices and Reactors," Argonne, Mlinois, January 10-12, 1974. J. Nucl. Mater. 53, 1-359 (1974).
}

ments of the energy-, angular-, and charge-distributions of such particles are needed, both from highly perfect flat surfaces and from surfaces of practical quality. Both single crystal and disordered surfaces (perhaps produced by keV particles) must be studied. Crystallographic effects are likely to be quite significant in the single crystal results and channeling studies may be a valuable technique for monitoring surface disorder as it proceeds. Such investigations are just beginning (Meischner and Verbeek, 1974; Sidenius, 1974; Andersen, et al., 1975) and need extension especially to lower energies. A theoretical description of neutral particle reflection is needed also. Such a description is impeded by a lack of reliable data on the electronic stopping cross sections of low energy $\mathrm{H}$ and $\mathrm{He}$ atoms and ions in solids.

Sputtering of the first wall of a CTR device leads both to erosion of the wall and to contamination of the plasma with wall material. Since bremsstrahlung energy losses from the plasma electrons depend very strongly on the charge of the impurity ions, very stringent limitations must be placed on contamination from the wall. Experimental measurements are needed of the sputtering yields of candidate CTR wall materials by $\mathrm{H}$ and $\mathrm{He}$ ions at energies from $100 \mathrm{eV}$ to $20 \mathrm{keV}$ or more. Since sputtering yields increase rapidly as the mass of the incident particle approaches that of the target atoms, the second order effect of sputtering by "self-ions" may also be significant, even though plasma contamination is kept small. Measurements in this area are needed also. The sputtering yield must be measured as a function of the angle of incidence of the ions on the surface. A fairly satisfactory theory of sputtering is available (Sigmund, 1969); it is probably least satisfactory for light atoms such as $\mathrm{H}$ or He. The study of small cluster (2 to 10 atoms) sputtering is of interest not only for its contribution to surface erosion and plasma contamination, but also because of the atomic line broadening effects expected in this transition from atoms to solids. At present the topic of sputtering by fast neutrons is highly controver sial, ${ }^{11}$ both as to the amount of sputtering and as to the state of aggregation of the ejected material. In this connection the recent 16 $\mathrm{MeV}$ proton sputtering experiments of Robinson and Thompson (1974) may be cited. Experimental work in progress (Jenkins et al., 1975; Harling et al., 1975) should clarify this area; until this is done, no sound judgement of its importance can be made.

The $\mathrm{He}$ and $\mathrm{H}$ which enter the first wall from the plasma (as well as $\mathrm{He}$ and $\mathrm{H}$ produced by neutron induced transmutations) can agglomerate into bubbles. If these are close enough to the surface, small blisters may appear which can eventually rupture and eject wall material and cold gas into the plasma. The general problem of

\footnotetext{
${ }^{11}$ Compare papers by M. Kaminsky and S. K. Das; M. Guinan; M. T. Robinson; T. H. Blewitt, et al .; and R. Behrisch, et al . included in the Proceedings of the Conference on Surface Effects in Controlled Thermonuclear Fusion Devices and Reactors, Argonne, Illinois, January 10-12, 1974. J. Nucl. Mater. 53, 1-359 (1974).
} 


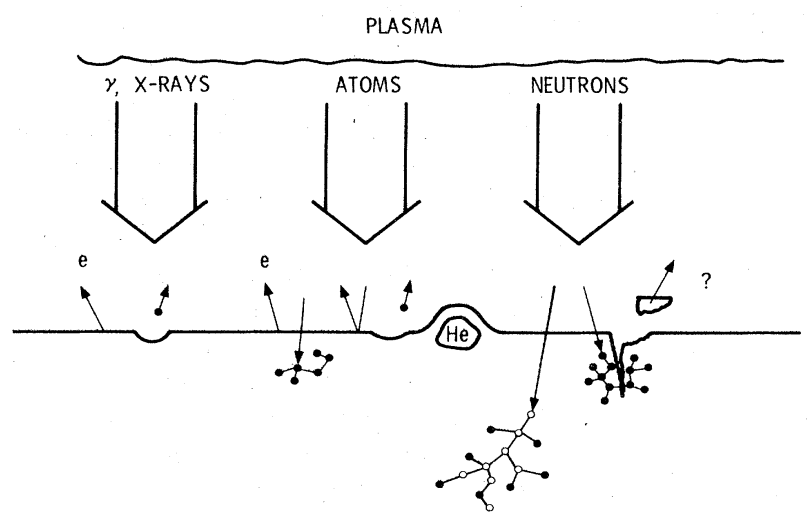

FIG. 3. Schematic diagram of the interaction of a plasma with a surface (see text).

gases in metals is discussed elsewhere in this report. However, it may be noted that experimental conditions in accelerator studies of gas retention using $\mathrm{MeV} \mathrm{H}$ and He ions are much more severe than can be anticipated in a CTR, where both dose rates and average ion energies will be much lower. Furthermore, the defect enhancement of diffusion of gas to the surface (or entrapment) as a result of a broad energy spectrum of damaging particles with different penetration depths has not been studied.

Radiation enhancement of surface rate processes is very likely to be significant in CTR devices. Enhancement of diffusion processes, chemical reactions, and precipitation may all occur. These can be expected to alter the mechanical properties of the wall. Such changes may significantly alter the conditions under which blister exfoliation takes place. The material may be subject to defect enhanced creep which may effectively soften the surface or to embrittlement which may harden it. In addition, precipitates and defect clusters may serve as sites for initiation of structural changes (including cracks) deeper in the stressed wall material. Considerable research in this technologically important area is required. It may be possible to take advantage of the new techniques of field-ion microscopy and scanning Auger spectroscopy as well as the specific ligand information available from Mössbauer spectroscopy. Nuclear reactions (Langley et al., 1974; Pronko and Pronko, 1974) and nuclear enhanced elastic scattering (Blewer, 1973 ; 1974) can serve as very useful tools for studying subsurface impurity atom distributions.

\section{B. Recommendations}

(1) The charge exchange and energy and particle reflection coefficients for $\mathrm{H}$ and $\mathrm{He}$ atoms and ions in the energy range from $100 \mathrm{eV}$ to $30 \mathrm{keV}$ or more must be investigated. The study needs to include not only ultra high vacuum surfaces but also surfaces covered with adsorbed hydrogen.

(2) A comprehensive understanding of the sputtering yields of refractory metals and high temperature insulators by hydrogen and helium ions from $100 \mathrm{eV}$ to $20 \mathrm{keV}$ or more must be achieved. Structurally well characterized materials will be required.

(3) Studies of neutron sputtering may be needed, but clarification of the experimental situation is needed to determine its importance.

(4) The retention, diffusion, precipitation and re-solution of impurities at and near surfaces under bombardment by relatively low energy particles must be understood. 


\section{INSULATORS}

\section{A. Introduction}

Although priority attention is usually given to radiation damage in metals and alloys, the characteristics of inorganic insulators in intense radiation fields are important to the success of nuclear energy conversion devices and are also important in other energy technologies. Our understanding of the effects of radiation on the insulating materials used in these technologies is inadequate. There is, for example, a demand for an understanding of the defects which affect electrical and thermal conductivity, gas permeation rates, sputtering yields, and structural integrity for refractory oxides, nitrides, glasses, and other insulators, under the hightemperature, high-neutron fluence conditions which will exist in controlled thermonuclear fusion reactors (CTR) (see Sec. II.A). The radiation effects problems associated with the rapidly developing field of optical wave guides and integrated optics in communications (Stickley et al., 1974), although not directly related to the fulfillment of national energy goals as is the CTR program, are of very substantial importance from an economic viewpoint.

The radiation sensitivity of metal-oxide-semiconductor (MOS) devices is directly related to the physical properties and structure of the $\mathrm{SiO}_{2}$ layer. These units, as components of integrated circuits, are economically important in space vehicles and missiles because of the light weight and the volume saving made possible with such circuits. Space radiation can bring about deleterious effects on operating conditions and these effects are predominantly associated with the oxide layer.

The defect structures of more complicated oxides, including $\mathrm{Al}_{2} \mathrm{O}_{3}$ which is of great CTR interest, are not well understood. For example, the point defects introduced into single crystal $\mathrm{Al}_{2} \mathrm{O}_{3}$ by fast electron irradiation cause the growth of an optical absorption band at $204 \mathrm{~nm}$, but this band has not been correlated with a specific defect (Arnold and Compton, 1960). ESR studies have not been very useful in radiation-induced defect identification because of the lack of hyperfine structure on the broad resonance peaks (Hughes and Henderson, 1972; Sonder and Sibley, 1972).

In glass research, studies of the properties of fused silica have a venerable history, but rapid progress has only been made in the past few years because of the economic importance to the semiconductor industry of an understanding of the defect structure of $\mathrm{SiO}_{2}$ layers on $\mathrm{Si}$. This information is needed not only because of the sensitivity of the $\mathrm{SiO}_{2}$ : $\mathrm{Si}$ device to radiation-induced defects in the oxide, but also because of the need to better understand impurity and defect diffusion, and interfacedefect configurations. Glasses are also of great interest for CTR applications (Development of Glass Electrical Insulator, 1973) because of the ease of deposition on metal substrates and the anticipation that impurities (transmutation products) can be incorporated readily into the glass structure. It is also felt that gas bubble formation may not be such an intense problem in glasses because of the easy diffusion of helium in these structures.
It is somewhat ironic that both our present very considerable understanding of the defect structure of insulating solids and our weaknesses in this area with regard to current high-priority goals, arise from our past heavy research involvement with the effects of radiation on alkali halide crystals (Hughes and Henderson, 1972; Sonder and Sibley, 1972). The concentration of effort on this class of insulators has been, to a large degree, due to the ease with which large high-quality crystals can be grown. The intense localization of trapped electronic charge at radiation-induced defect trapping sites, peculiar to ionic systems, has allowed the experimental investigative tools of optical absorption, luminescence, and electron spin resonance (ESR) to be developed to a high degree of sophistication. As a consequence, the defect structure of the alkali halides and the mechanism of defect introduction by irradiation are rather well understood. This knowledge has been extremely useful when similar investigative techniques have been applied to other classes of insulating materials. Unfortunately, many materials are less amenable to such attacks either because of difficulty in obtaining good quality, high-purity material, or because the experimental techniques fail. The alkaline earth oxide $\mathrm{MgO}$, for example, has long been studied, but success in understanding the defect structure has been slow and is directly related to the gradual development of high-purity crystal growth methods (Hughes and Henderson, 1972; Sonder and Sibley, 1972).

For the materials of greatest interest in the CTR program, the radiation induced atomic displacements are governed by Coulomb and hard-sphere interactions. The ion displacement mechanism (Pooley-Hersh effect (Pooley and Runciman, 1966; Hersh, 1966)) which can occur when electronic energy is deposited in alkali halides is not likely to be important in these materials. There is, however, recent evidence (Arnold, 1974) which indicates that the charge-state of defects in insulators, particularly $\mathrm{Al}_{2} \mathrm{O}_{3}$, is of great importance in determining the radiation-induced dilation. For example, ion implantation induced lattice expansion in $\mathrm{Al}_{2} \mathrm{O}_{3}$ can be greatly reduced by electron injection or proton implantation. It is worth pointing out that, since there are no conduction electrons in insulator crystals, ionization caused by the radiation field can have enormous effects upon electrical resistivity; e.g., Hughes (1973) has measured electron mobilities as high as $20 \mathrm{~cm}^{2}$ volt ${ }^{-1} \mathrm{sec}^{-1}$ in fused silica under pulsed irradiation. As a rule of thumb, the energy per electron-hole pair is about 3 times the bandgap energy $E_{g}$ (Billington and Crawford, 1961). Hence, a $2 \mathrm{MeV}$ particle creates around $10^{5}$ electron-hole pairs as it is stopped in an insulator with $E_{g}=7 \mathrm{eV}$. For a typical lifetime of $10^{-7} \mathrm{sec}$ and a range of $1 \mathrm{~mm}$, a $10^{14} \mathrm{~cm}^{-2} \mathrm{sec}^{-1}$ beam of electrons produces a steady-state carrier concentration of $10^{13}$ electrons $/ \mathrm{cm}^{3}$. In many ionic crystals the room temperature mobility of electrons is about 10 $\mathrm{cm}^{2}$ volt $^{-1} \mathrm{sec}^{-1}$; therefore this level of exposure could be expected to produce a resistivity of about $10^{5} \mathrm{ohm} \mathrm{cm}$ compared to a normal value of $10^{12}-10^{15} \mathrm{ohm} \mathrm{cm}$. Because of its much shorter range, a $2 \mathrm{MeV}$ proton beam 
of the same intensity would decrease the resistivity even more. Trapping of the electrons by impurities would reduce the lifetime and increase the resistivity. These changes are only semipermanent, being greatly affected by both heat and light. Conductivity changes may be serious in certain applications and need to be thoroughly explored. Increased electron and hole concentrations also have an important effect upon the nature and amount of lattice damage retained by the crystals. In the following sections we discuss specific problems of interest and have emphasized those questions or areas that need in-depth research.

\section{B. Discussion of specific problem areas}

\section{Reactor materials}

Insulator radiation effects problems exist for all proposed CTR designs, i.e., tokamaks, mirror machines, or theta pinch. Common to these designs are the problems of ensuring good electrical resistivity for high-voltage and magnet coil insulation under high intensity radiation fields. For the LASL theta pinch concept, however, the insulator problems (Krakowski and Clinard, 1974) are different and formidable, and the proper choice of material for the first wall is crucial to the successful operation of the device. In this design, the insulator $\left(0.3 \mathrm{~mm} \mathrm{Al} \mathrm{O}_{3} \mathrm{O}_{3}\right.$ ceramic is the prototype insulator for design purposes) constitutes, together with niobium metal structural backing $(1.0 \mathrm{~mm})$, the plasma-containing first wall of the reactor. The insulator is needed to prevent breakdown through the plasma due to the large voltages induced when the fast-rising implosion heating magnetic field is applied at the beginning of the $10 \mathrm{sec}$ duty cycle. During the application of this field $(\sim 10 \mathrm{msec})$, the design specifications call for a resistivity $\geqslant 10^{6} \Omega-\mathrm{cm}$ and a dielectric strength of $\geqslant 100 \mathrm{kV} / \mathrm{cm}$ at the reactor operating temperature $\left(\sim 800^{\circ} \mathrm{K}\right.$ with $\sim 300^{\circ} \mathrm{K}$ transients). During the duty cycle, the insulator is exposed to a total neutron flux of $\sim 10^{15} \mathrm{n} / \mathrm{cm}^{2}-\sec \left(\sim 2 \times 10^{14} 14 \mathrm{MeV} \mathrm{n} /\right.$ $\mathrm{cm}^{2}-\mathrm{sec}$ ) and a bremsstrahlung energy flux of $\sim 70 \mathrm{~J} / \mathrm{cm}^{2}$ per 10 sec pulse. A survey of possible insulators for which data are available and which meet the resistivity requirement at high temperature has produced the following candidates: $\mathrm{Al}_{2} \mathrm{O}_{3}, \mathrm{BeO}, \mathrm{HfO}_{2}, \mathrm{MgO}, \mathrm{SiO}_{2}$ (vitreous), $\mathrm{Y}_{2} \mathrm{O}_{3}, \mathrm{AlN}$, $\mathrm{BN}$, and $\mathrm{Si}_{3} \mathrm{~N}_{4} \cdot \mathrm{SiC}$ is also of great interest (Hopkins, 1974) for first-wall applications, but its resistivity seems to be too low for the theta pinch device. Mixed oxides, aluminates, spinels, zirconates, garnets, and glasses are of interest but data on these materials are not readily available.

The theta pinch first-wall insulator requirements also include good thermal conductivity in order that excess thermal energy in the wall can be removed during the plasma cooling stage $(\sim 2 \mathrm{sec})$ and before the next power cycle. Fast-neutron irradiation is known (Berman et al., 1954; Berman et al., 1960; Reichelt et al., 1970) to decrease the thermal conductivity of $\mathrm{Al}_{2} \mathrm{O}_{3}$ and crystalline $\mathrm{SiO}_{2}$ (Berman et al., 1950) because of the introduction of phonon scattering centers but little information exists on this property change in the other materials of interest. The radiation induced expansion of the insulator may cause separation from the metal substrate, if excessive, or if different than the expansion of the metal. A survey of this important parameter change has recently been made and shows that $\mathrm{Y}_{2} \mathrm{O}_{3}$ shows virtually no irradiation growth for fast-neutron fluences of $\sim 10^{22} / \mathrm{cm}^{2}$. Very little (Primak, 1972) is known about void formation, as distinct from lattice expansion, in insulating materials at highneutron fluences and high temperature. The production of $\mathrm{He}$ and $\mathrm{H}$ in $\mathrm{Al}_{2} \mathrm{O}_{3}$ due to transmutation is estimated (Krakowski and Clinard, 1974) to be $1685 \mathrm{ppm} / \mathrm{yr}$ and $975 \mathrm{ppm} / \mathrm{yr}$, respectively. The use of glass as a firstwall material is attractive, as mentioned above, because of the rapid diffusivity of He in silicate glasses. However, bubble formation in the metal backing and migration to the metal/insulator interface could also bring about spallation of the insulator from the composite (Krakowski and Clinard, 1974).

Ion, neutral atom, and neutron sputtering of the firstwall under operating conditions represents an important factor for which more research is needed because of possible excessive wall and divertor erosion, and also because of plasma contamination and quenching from sputtered impurities. Neutron sputtering should be small, but particulate ejection from $\mathrm{Nb}$ has recently been reported (Kaminsky et al., 1974). The status of plasma-wall interactions has recently been reviewed (Vernickel, 1974). (See Sec. VIII.)

Many of the CTR designs utilize molten lithium as coolant, tritium breeder, and neutron moderator. The flow of lithium across magnetic field lines causes currents to flow in the tube wall and this in turn causes pressure drops because of the effective increase in viscosity. To reduce the pressure drop, it would be desirable to have an insulating coating on the tube walls. In this application, the additional problem of compatibility of the insulator with molten $\mathrm{Li}$ is presented. It would also be desirable (Hickman, 1972) to use the insulator as a permeation barrier against tritium diffusion in order to confine the tritium and to prevent plant contamination. Hydrogen permeation data is scarce for insulating compounds other than the oxides and even less is known about the effects of irradiation on this property.

The use of lasers to initiate fusion in thermonuclear reactors (LCTR) by implosion compression of a D-T pellet is receiving much research effort both in the U. S. and abroad (Nucholls et al., 1973). In this application the laser-beam handling and transport system utilizes windows and mirrors for beam focusing, deflection, and switching. In addition to the need to withstand damage due to the intense laser beam, some of the optical elements will be exposed to $x$-rays, $\gamma$-rays, and neutrons. The use of $\mathrm{CO}_{2}$ laser light $(10.6 \mu \mathrm{m})$ in prototype reactor designs has limited the window materials to $\mathrm{NaCl}$, $\mathrm{KCl}$, Ge, GaAs, CdSe, etc. While considerable information exists concerning the laser damage threshold in these materials (Williams and Frank, 1974), information is needed on the effects of radiation and ablative material from the reactor cavity on optical and structural properties.

The radiation effects problems associated with insulators in fusion reactor environments are also discussed in a very recent article by A. Holmes-Siedle (1974). 


\section{Ancillary opportunities}

The major problem facing insulator materials used in fission or fusion reactor systems will be high radiation fields and fluences. Not only will there be instantaneous effects such as ionization currents, but the mechanical and optical properties of the material will be strongly and most likely adversely affected. This means that swelling, creep and embrittlement will occur as well as a degradation in the insulating properties of the material. The optical properties, even infrared absorption, of window materials are known to be affected by radiation. To this end, methods of suppressing the production of defects by photochemical processes, such as impurity doping, must be explored and studies of materials in simulated high current and high dose situations must be undertaken.

Methods must be sought to suppress stable defect production, and to decrease the transient conductivity caused by secondary electrons in new materials as well as in insulators already in use. Thus, an intensive study of the role of impurities as defect traps and electronhole recombination centers will be required. But aside from evaluating radiation resistance of materials, real opportunities for using radiation effects in fruitful ways should be explored. For example, radiation can be used in strengthening materials, e.g., the recent work on surface recrystallization of glass (Krefft and Arnold, 1973). Dosimetry is another area where insulators have contributed in valuable ways. Radiation damage processes in these dosimeters-whether they be a glass such as silver activated phosphate glasses or $\mathrm{MgO}$ - for both gamma and neutron detection must be understood.

\section{Research priorities}

\section{Reactor materials}

(i) High dose-high flux radiation damage studies with special attention to radiation enhanced processes in insulators such as radiation enhanced diffusion, creep, defect interaction rate (void formation), etc.

(ii) Identification of primary radiation-induced defects in insulators of interest and their relaxation products and annealing characteristics.

(iii) Investigations of radiation-induced changes in electrical resistivity, dielectric breakdown and thermal conductivity.

(iv) Studies of mechanical property changes (lattice expansion, void formation, thermal stress, grain spallation) of both the insulator and the insulator-metal composite and the effect of defect charge state on the magnitude of these changes.

(v) Measurements of hydrogen permeation and its change under irradiation.

(vi) Sputtering of insulators and identification of the charge-state of ejected ions.

\section{Crystal growth}

There is an urgent need for research into insulator crystal growth and characterization in order to provide a base of fundamental material information for subsequent radiation studies. 


\section{SEMICONDUCTORS}

Although semiconductors themselves are likely to have a small direct role in the energy problems of nuclear reactors, the advanced understanding of radiation effects in semiconductors can serve perhaps as a guide to the attack on radiation effects problems in other materials. The advanced understanding of radiation ef fects in silicon, for example, has been of great importance to the semiconductor industry in areas such as ion implantation doping techniques. These techniques are almost identical to those which can be used for the simulation of neutron damage as well as for the study of enhanced diffusion and transmutation effects. In addition, the role of semiconductors as detectors of nuclear radiation is very important and needs continuing work.

First, we will discuss the status of our understanding in semiconductors. The field is extensively covered in a recent reference work and in the proceedings of several Defect Conferences and the various Ion-Implantation Conferences. ${ }^{12}$ We then return to the implications of this work.

In a sense we have a more detailed understanding of defects in a semiconductor, silicon, than in any other system, but that knowledge emphasizes how little we know. The reason for our advanced knowledge in silicon is that Electron Spin Resonance (ESR) experiments have been systematically carried out yielding detailed defect models. These studies have resulted in the identifications of a number of vacancy defects $\left(\mathrm{V}^{ \pm}, \mathrm{V}_{2}{ }^{ \pm}, \mathrm{V}_{3}, \mathrm{~V}_{4}\right.$, and $V_{5}$ ) and of vacancy plus impurity pairs (e.g., plus oxygen, P, Sb, As, Al, B, Ga, etc.). Annealing studies of such defects reveal the panorama of the disappearance of simple defects, the evolution and then the dissolution of more complex defects, resulting ultimately in dislocationtype defects which also disappear. While there are a number of gaps in the vacancy picture, a coherent view is emerging. This is not so on interstitial defects. The

${ }^{12}$ See the following references:

(a) Point Defects in Solids, edited by J. H. Crawford, Jr. and L. Slifkin (Plenum, N. Y., 1974) Vol. 2;

(b) Lattice Defects in Semiconductors 1974, Proceedings of the 1974 International Conference on Lattice Defects in Semiconductors, Freiburg, July 22-25, 1974, edited by F. A. Huntley (The Institute of Physics, London, 1975);

(c) Radiation Damage and Defects in Semiconductors, Proceedings of the Defect Conference at Reading, edited by J. E. Whitehouse (The Institute of Physics, London, 1973);

(d) Radiation Effects in Semiconductors, Proceedings of the Defect Conference at Albany, edited by J. W. Corbett and G. D. Watkins (Gordon and Breach, New York, 1974);

(e) Radiation Effects in Semiconductors, Proceedings of a Conference at Santa Fe, edited by F. L. Vook (Plenum Press, N. Y., 1968);

(f) Ion Implantation in Semiconductors, Science and Technology, Proceedings of the IV International Conference on Ion Implantation in Semiconductors and Other Materials, Osaka, 1974, edited by S. Namba (Plenum Press, N. Y., 1975);

(g) Ion Implantation in Semiconductors and Other Materials, Proceedings of a Conference, edited by B. L. Crowder (Plenum Press, N. Y., 1973);

(h) Ion Implantation in Semiconductors, Proceedings of a Conference, edited by I. Ruge and J. Graul (Springer Verlag, N. Y., 1971). "missing self-interstitials" have been a problem for some time, but recent theoretical work and companion experimental studies seem to be bearing fruit. In any event it seems clear that the self-interstitial (and some impurity interstitials, e.g., boron and carbon) are probably "interstitialcy"-type defects (such as the splitinterstitials found in metals and alkali halides) rather than having the canonical interstitial configuration, as does the $\mathrm{Al}$ - interstitial in Si. Further, the interstitials can agglomorate and precipitate in various complexes. Still a well-established picture of the interstitial defects in $\mathrm{Si}$ is not at hand. ${ }^{13}$

ESR has also yielded a large number of spectra in diamond, in SiC and in II-VI compounds. In the latter case chalcogenide and metal vacancies have been identified in a number of compounds, establishing a firm foundation upon which to build subsequent knowledge. In $\mathrm{SiC}$ and diamond extensive defect identification has not been carried out, but the observation of a number of spectra holds promise of establishing a defect inventory comparable to (or exceeding) that in silicon. ESR in Ge and III-V compounds is more difficult than the other systems and the results not as promising.

ESR is certainly not the only measurement made. Its virtue has been the detailed knowledge it gives on the atomic level-giving symmetry information about the defect. As we have seen in the work on metals in this report, other techniques can also give symmetry information. Indeed in semiconductors, the stress response of optical and photoelectric transitions has proven to be a powerful technique. Recent internal friction results in silicon indicate the power of this approach. Still we must emphasize the importance of the further exploitation of these approaches (e.g., internal friction, elastic constant, small angle and diffuse x-ray scattering measurements), even in, and perhaps especially in, systems where ESR results exist.

In summary, an extensive defect inventory exists in $\mathrm{Si}$; there is a lesser defect inventory in II-VI's; and there is promise of one in diamond and SiC. In Ge, largely based on electrical measurements, there is an extensive model (in some cases, several models) describing defect processes; the models in III-V compounds are not as well established. There is need for much more work leading to the understanding of defect processes in every semiconductor.

We also note that defect migration mechanisms are not well established in semiconductors. For example the interstitials apparently move by an athermal mechanism in $\mathrm{Si}$ and $\mathrm{Ge}$, i.e., migrate long distances at or below $4{ }^{\circ} \mathrm{K}$. There are examples where migration ener gies are charge-state dependent. There is clear evidence in CdS (as in some metals) that collisional recoils due to a bombarding beam can enhance defect migration. Much more work is needed to investigate

\footnotetext{
${ }^{13}$ In view of all the other discussion in this report about voids, it is appropriate to note that voids have not been observed in semiconductors, although extensive experimentation along these lines has not been carried out.
} 
these topics systematically.

We note that in semiconductors, as apparently in metals and alkali halides, there are difficulties in reconciling results from high temperature equilibrium (e.g., diffusion) measurements and from low temperature radiation damage studies. Part of the difficulty is clearly in the interpretation of self-diffusion measurements (e.g., there are quite high entropy factors in a number of semiconductors), but we do not pretend that a ready solution to the controversies in this field is at hand.

The theory of defects in semiconductors, although marked by substantial progress in recent years, is still not adequate and represents a major area of opportunity for further work. The theory needs to encompass many-electron effects, non-neutral charge states, polarization effects, etc. Hence the need for a satisfactory theory includes the theory of static defect states (their energies, wave functions and electronic transitions), defect migration, interaction and formation.

An important part of the understanding of defects is that of defect production. Here the understanding for semiconductors is clearly behind that in the metals; dynamic computer calculations of damage events, as are available in metals, do not exist for semiconductors. The reason is that the semiconductor clearly requires that that valence bonds be included (i.e., the atom-atom interactions are not just two-body, pair-wise interactions). Further, what work there is, indicates that the constituents of the Frenkel pair may not just be neutral (e.g., $\left.\mathrm{I}^{0}+\mathrm{V}^{0}\right)$ but may become charged during their formation (e.g., $\mathrm{I}^{+}+\mathrm{V}^{-}$), necessitating the inclusion of the Coulomb interaction and polarization effects.

There are extensive data on defect production, including the displacement production of identified defects. The temperature, orientation and Fermi-level dependence has been studied in some cases. Information on the number of "free defects" (i.e., those escaping correlated annihilation) and on capture radii of some impurities for some defects have been found in a few instances. In no case, however, is a full, satisfactory picture of defect production established.

Furthermore there are instances of subthreshold dam- age and of damage produced by ionization alone! (The latter observed in InSb, and in Si.) While there are uncertainties and controversies in these areas, we must note that the state of our understanding of these areas is unsatisfactory.

Let us jump, for the moment, to the question of the relevance of such studies, i.e., their technological and societal motivation. Certainly one of the early motivations was military, e.g., concern for nuclear weapons effects on semiconducting devices. The space program has also provided a motivation since the satellite solar cell power supplies deteriorated in the solar wind and Van Allen belt particle fluxes. The renewed interest in terrestrial solar cell power sources could also profit from increased semiconductor research, but to a lesser extent from particle-semiconductor interaction studies than from conventional studies of device degradation in use. The use of ion implantation to improve the efficiency of solar cells and the use of ion surface analysis techniques to analyze device structures are examples where particle-solid interaction studies can help technology. As noted elsewhere in this report the pulsed plasma machines will require insulators, but this is not likely to involve semiconductors. On the other hand, $\mathrm{SiC}$ is of interest for CTR walls since a large proportion of the sputtered particles are ions and thus easier to control.

In our view the main technological motivations for particle-semiconductor studies is the multi-billion dollar semiconductor industry itself. Major portions of this industry are adding ion implantation to their library of manufacturing techniques. But ion implantation creates complex defect structures whose nature and properties need to be unraveled. Furthermore the defects produced in implantation, as well as the attendant collisional recoils and ionization can all produce enhanced diffusion, whose features need to be established. We note, that a special opportunity exists for the physics community to establish the separate aspects which may exist for the field-enhanced, defect-enhanced, recoilenhanced and ionization-enhanced diffusion of defects, all of which mechanisms may occur simultaneously in an ion-implantation experiment. 


\section{SUPERCONDUCTIVITY}

\section{A. Introduction}

Many of the concepts of a controlled thermonuclear reactor involve plasma containment by very strong magnetic fields ( $\sim 50-150$ kilogauss), to be produced by superconductor magnets. The neutrons emitted by the fusion reaction are partially absorbed by the blanket and shields surrounding the fusion chamber, but some will bombard the superconducting materials of the magnet; the magnitude of this neutron flux will be determined by the best compromise for liquid helium loss due to absorption of all forms of radiant energy, magnet size and the effect of irradiation on the properties of superconductors. Hence it is essential that the effects of neutron irradiation on the properties of superconductors be well established and well understood. Also, it is probable that in the process of understanding the effects of radiation on superconductors we may gain increased understanding of the complex subject of radiation damage.

\section{B. Present status of knowledge}

Type II superconductors can be divided into three groups for present purposes:

(a) pure metals and well-annealed single phase alloys, which have low or intermediate transition temperatures $T_{c}$, and low critical fields $H_{c 2}$;

(b) commercial alloys, which have intermediate $T_{c}$ and $H_{c 2}$;

(c) compounds (e.g. A-15 type, laves phases, $\mathrm{NaCl}$ type) which have high $T_{c}$ and $H_{c 2}$.

\section{Group (a)}

It is established that the upper critical field can be changed by neutron irradiation in direct proportion to the change in electrical resistivity produced by the irradiation, in good agreement with theory. $T_{c}$ for these materials is little affected by neutron irradiation $\left(\sim 0.1{ }^{\circ} \mathrm{K}\right.$ for neutron irradiation at room temperature to a dose $\sim 10^{20} \mathrm{n} / \mathrm{cm}^{2}$ ) (Ullmaier, 1973).

The magnetic fluxoids in these materials are strongly pinned by the defects produced by neutron irradiation. After irradiation with electrons, which produces a random distribution of vacancy-interstitial pairs, there is a small fluxoid pinning effect which rapidly saturates with increasing defect concentration. This effect is well understood and is in agreement with theory (Ullmaier, 1973). After neutron irradiation at $4{ }^{\circ} \mathrm{K}$ strong pinning of fluxoids occurs. Annealing studies show it is the point defects which pin, but by comparison with the electron irradiation results the pinning must be related to the nonuniform distribution of the defects due to the displacement cascades. After room temperature irradiation the fluxoids are also strongly pinned, presumably by the small dislocation loops resulting from this irradiation. This pinning results in increases in the magnetic remanance in metals and alloys initially in the annealed condition, and the critical current $\mathrm{I}_{c}$ is increased accordingly (Sekula, 1971). The mechanism of this fluxoid pinning is not well understood.

\section{Group (b)}

$T_{c}$ for these materials is also little affected by neutron irradiation $\left(\sim 0.1^{\circ} \mathrm{K}\right)$. The fluxoids in these materials are strongly pinned by the dislocations and dislocation cell walls, resulting in intermediate to high values of $I_{c}$ at large values of applied field. The effect of irradiation is to reduce $\mathrm{I}_{c}$; multifilamentary composite wires of $\mathrm{NbTi}$ were irradiated at $60 \mathrm{C}$ to a dose of $6 \times 10^{19}$ $\mathrm{n} / \mathrm{cm}^{2}$, and a reduction in $\mathrm{I}_{c}$ at $40 \mathrm{kG}$ of $18 \%$ was observed (Parkin and Schweitzer, 1974). Similar effects were found in low magnetic fields after $4{ }^{\circ} \mathrm{K}$ irradiations (Brown et al., 1974). These effects are poorly understood. No measurements of $I_{c}$ at magnetic fields higher than about $30 \mathrm{kG}$ after low temperature neutron irradiation have been made.

\section{Group (c)}

Neutron irradiation at room temperature above a certain critical fluence results in catastrophic decreases in $T_{c}, H_{c_{2}}$ and $\mathrm{I}_{c}$ in A-15 compounds. For doses $z 3 \times 10^{18}$ $\mathrm{n} / \mathrm{cm}^{2}$ these properties decrease rapidly with increasing dose; e.g., in $\mathrm{Nb}_{3} \mathrm{Sn}, T_{c} \approx 3^{\circ} \mathrm{K}$ after a dose $\sim 5 \times 10^{19} \mathrm{n} / \mathrm{cm}^{2}$ (Sweedler, 1974). There are similar drastic changes in $H_{c 2}$ and $I_{c}$. To recover these property changes it is necessary to anneal to $750 \mathrm{C}$. Apparently these effects are associated with a decrease in the degree of order in these compounds due to the atomic displacements resulting from the irradiation. Neutron irradiations of these materials at $4{ }^{\circ} \mathrm{K}$ are in progress.

Apparently any pinning effects of the fluxoid lattices in these superconductors is overwhelmed by the disorder ing effects. No irradiations of other types of high $H_{c 2}$ high $T_{c}$ superconductors have been reported, but some experiments are in progress.

\section{Basic unknowns}

(1) An understanding of the fluxoid pinning mechanisms for defects produced by neutron irradiation [ Groups (a) and $(b)]$.

(2) The interrelations of fluxoid pinning by dislocations and dislocation substructures and by radiation produced defects (point defects and/or small dislocation loops).

(3) The effects of irradiations at low temperatures on $\mathrm{I}_{c}$ at high fields in Group (b) materials (known for proton irradiation).

(4) Confirmation that the disorder resulting from neutron irradiation is correlated with changes in the superconducting properties of A-15 compounds. An understanding of the changes in electronic structure associated with order-disorder which determine the superconducting properties.

(5) Superconducting properties of A-15 compounds after $4^{\circ} \mathrm{K}$ irradiation.

(6) Effects of irradiation on superconductors with other crystal structures.

\section{Promising areas of research}

(1) Measure the superconductor parameters $\mathrm{I}_{c}, H_{c 2}$, and $T_{c}$ as a function of fluence, particularly at $4{ }^{\circ} \mathrm{K}$.

(2) Measure the recovery behavior of $T_{c}, I_{c}$ and $H_{c 2}$ 
after irradiation.

(3) Study the stability of sample coils irradiated at $4{ }^{\circ} \mathrm{K}$ and compare the results with stability theories.

(4) Study irradiation effects in superconducting materials as a function of their crystal structure.

(5) Perform basic physical measurements on irradiated superconductors, e.g., heat capacity, resistivity and magnetic susceptibility.

(6) Study the influence of metallurgical variables e.g., (heat treatment, fabrication techniques, impurities, etc.) on the parameters of superconductors.

(7) Investigate the properties of magnetic fluxoids including the pinning of fluxoids by defects. 


\section{INTERACTIONS BETWEEN UNIVERSITIES AND LABORATORIES}

Fruitful interaction between the university research community and the large government supported laboratories has developed in a number of instances over the years with considerable benefit to both. Longer range perspectives derived from university research have been injected into the mission oriented objectives of the government laboratories, and an understanding of how basic and applied research interact as well as new appreciations of current technological interests are carried back to the universities. The purpose of this section is to emphasize the need for enhancing this type of interaction and to discuss effective modes for promoting it.

Some industrial laboratories are involved in programs that study radiation damage effects or the use of radiation in device fabrication, but most of the research involving radiation effects is done at large government supported laboratories, especially ERDA laboratories. Therefore, in this discussion "laboratory" will usually be defined as a government supported laboratory where unique large radiation facilities are located, and energy programs are given high priority. This section will be divided into two parts: (1) Present profitable programs and (2) New programs suggestions.

(1) A number of successful programs are currently being pursued which bring together laboratories and universities. The need to help students mature and to further mutual interaction of professors and laboratory staff is met at present by summer research visits sponsored by organizations at the various laboratories and funded by ERDA. These programs are extremely valuable and certainly should be expanded as funds permit. The use of the unique facilities at various laboratories is another aid to university programs. The possibility of conducting collaborative experiments with the scientists operating these facilities offers a faculty me mber an opportunity to add to his experimental capabilities, and the laboratory the opportunity to enhance the research program. In addition some laboratories have speaker lists from which universities can select speakers for colloquia (these programs of late have not been too successful owing to a lack of supplemental funds available in small universities); others have a sabbatical leave policy which enables their employees to spend extended periods at a university.

In addition to the mutual benefits of the student and faculty research-participation programs the laboratories have benefitted by the identification of a number of high-caliber people who have been subsequently employed by the laboratories. These programs will need to be expanded if the anticipated shortage of available scientists in this research area becomes a reality. It should be remembered in this connection that the missions of laboratories and universities are usually quite different. The universities cannot become research arms of the government, moving from one crisis area to another, nor can most laboratories' primary mission be service to universities.

(2) Where possible new collaborative programs should be developed and some of the existing informal ones should be strengthened, formalized and publicized. Of ten the academic people who could most benefit from participation in such programs are at small universities where information about such arrangements is not readily available. An effort must be made to disseminate this information to the academic community as a whole in order to take advantage of some of the important resources both in innovative ideas and research facilities that exist at some of the smaller schools. We propose two specific new programs to do this, but many other variations of these proposals could be made. One program would be the formal coordination of a research program at a university with one at a laboratory. The mechanism of this coordination would be that the funding agency for the laboratory would set aside some funds for supporting special research problems at universities which are of particular interest to the laboratories. A joint proposal from the laboratory and the university groups would be submitted which would request funding for a professor and an assistant plus some travel and maintenance for the academic year. In the summer the professor and assistant would be at the laboratory participating in research with their joint laboratory group. This approach will bring new blood to the laboratory and allow academic people to become acquainted with new techniques and the missions of the technological community.

Another program we would like to suggest is a series of symposia on a continuing basis which are addressed to current missions of the technological community, both national laboratories and industries. These symposia would be structured after the Gordon Conferences and would consist of selected university people (especially those at smaller schools with research capabilities) and project scientists from laboratories. The symposia would deal with current technological missions, and hopefully would convey the idea that basic research and applied research are mutually supportive. It would also further the recognition of the interconnection of academic research with the technological goals of society.

Wherever feasible, it would be desirable to extend such collaborative interactions to industrial research institutes or industrial laboratories. 


\section{ACKNOWLEDGMENT}

The senior participants responsible for the preparation of this report would like to thank the many briefers who made presentations at the workshop.

The study group consisted of a working committee of senior and junior members, who were joined for varying periods of time by 35 additional briefers expert in a broad range of fundamental and applied areas related to radiation effects on materials. The meeting was held June 17-28 1974, at Brookhaven National Laboratory. After six days of extensive presentations and discussions, the committee began the preparation of this report.

We would like to thank Brookhaven National Laboratory for its hospitality and efficiency in hosting the meeting on very short notice. We would especially like to thank the Division of Physical Research of the U.S. Atomic Energy Commission for their financial support of the workshop. We also would like to acknowledge several people who were major contributors to particular chapters of this report. Professor W.A. Sibley, Oklahoma State University, contributed strongly to both Sec. IX and XII. G. W. Arnold, Sandia Laboratories, contributed a major part of Sec. IX. Professor R. A. Yeske, University of Illinois, helped write Sec. VII. The committee wishes to thank $\mathrm{Dr}$. S. A. Goudsmit for his very useful editorial suggestions and contributions. 


\section{REFERENCES}

$\mathrm{AEC} / \mathrm{CONF}-71062$
1971
A EC/CONF-7404
1974

AEC/Symposium
31,1974

31, 1974

\section{$\mathrm{AEC} / \mathrm{WASH}$ \\ 1240-73, 1973

\begin{abstract}
AEC/WASH-1206, 1972
\end{abstract}

Alefeld, 1972

Andersen et al ., 1975

A rnold et al ., 1974

A rnold and Compton, 1960

ASTM, 1974

Badger, 1973

Balluffi and Seidman, 1971

Bates, 197x

Bauer, 197x

Beaman et al ., 1964
U. S. Atomic Energy Commission, 1971, CONF-710624, Proceedings of the Internal Working Sessions on Fusion Reactor Technology, Oak Ridge National Laboratory, June 28-July 2, 1971

U. S. Atomic Energy Commission, 1974, CONF-740402, Proceedings of the First Topical Meeting on the Technology of Controlled Nuclear Fusion, April, 1974.

U. S. Atomic Energy Commission, 1974, CONF-72111, A EC Symposium Series 31, Technology of Controlled Thermonuclear Fusion Experiments and the Engineering, Aspects of Fusion Reactors (CONF-72111) edited by E. Linn Draper, Jr.

"Critical Questions .in Fundamental Radiation Effects Research;” U. S. A tomic Energy Commission, 1973, Report WASH 1240-73, edited by L. C. Ianniello.

U. S. Atomic Energy Commission, 1972, Report WASH-1206, "Fusion Reactor First Wall Materials," edited by L. C. Ianniello.

Alefeld, G., 1972, Ber. Bunsenges Phys. Chem., 76, 746.

Andersen, H. H., T. Lenskjaer, G. Sidenius, and H. S $\varnothing$ rensen, 1975, J. Appl. Phys. (in press).

Arnold, G. W., G. B. Krefft, and C. B. Norr is, 1974, App1. Phys. Lett. 25 540 .

Arnold, G. W., and W. D. Compton, 1960, Phys. Rev. Lett. 4, 66.

"Proposed Standard Recommended Practice for Neutron Radiation Damage Simulation by Charged Particle Irradiation," prepared under the Jurisdiction of the E-10 Committee of the ASTM, Code E521.00, 1974.

Badger, B., et al., UWMAK-1, A Wiscons in Toroidal Fusion Reactor Design, UWFDM-68, November, 1973.

Balluffi, R. W., and D. N. Seidman, in "Radiation Induced Voids in Metals" AEC Symposium, Albany, N. Y., June 9-11, 1971, edited by J. W. Corbett. and L. C. Ianniello, AEC Symposium Series, CONF-710601.

Bates, J. L., Battelle-Northwest Laboratories, 1111, (private communication).

Bauer, A. A., Batelle-Columbus Laboratories, 1111, (private communication).

Beaman, D. R., R. W. Balluffi, and R. O. Simmons, 1964, Phys. Rev. 134, A 532 .
Beeler, 1966

Berger et al., 1973

Berman et al., 1950

Berman et al., 1954

Berman et al., 1960

Bethe, 1973

Billington and Crawford, 1961

Birnbaum et al., 1974

Birnbaum and Wert, 1972

Blackburn, 1966

Blewer, 1973

Blewer, 1974

Brenner and McKinney, 1970

Brenner and Seidman, 1975

Brice, 1970

Brice, 1973

Brown and Moak, 1972

Brown et al., 1974

Bullough and Nelson, 1974

Burton, 1971
Beeler, Jr., J. R., 1966, Phys. Rev. 150, 470 .

Berger, A. S., D. N. Seidman, and R. W. Balluffi, 1973, Acta Metall. 21, 123.

Berman, R., P. G. Klemens, F. E. Simon, and T. M. Fry, 1950, Nature $166,864$.

Berman, R., E. L. Foster, and H. M. Rosenberg, 1954, Defects in Crystalline Solids, Report of the Bristol Conf. (The Physical Society, London, 1954).

Berman, R., E. L. Foster, B. Schneidmess, and B. M. A. Tirmizi, 1960, J. Appl. Phys. 31, 2156.

Bethe, H., 1973, Advanced Nuclear Power, Report of the Cornell Workshops on the Major Issues of a National Energy Research and Development Program, Cornell U. P., 1973.

Billington, D. S., and J. H. Crawford, 1961, Radiation Damage in Solids (Princeton, U. P. Press).

Birnbaum, H. K., M. Grossbeck, and S. Gahr, 1974, Hydrogen in Metals edited by I. M. Bernstein and A. W. Thompson (A.S.M., Metals Park, 1974), p. 303 .

Birnbaum, H. K., and C. Wert, 1972, Ber. Bunsenges. Phys. Chem. 76, 806.

Blackburn, R., 1966, Metall. Rev., 11, No. 110, 159.

Blewer, R. S., 1973, Appl. Phys. Lett. 23, 595 .

Blewer, R. S., 1974, in Applications of Ion Beams to Metals, edited by S. T. Picraux, E. P. EerNisse and F. L. Vook, (Plenum Press, N. Y., 1974), p. 557.

Brenner, S. S., and J. T. McKinney, 1970, Surf. Sci. 23, 88.

Brenner, S. S., and D. N. Seidman, 1975, Radiat. Eff. 24, 73.

Brice, D. K., 1970, Radiat. Eff., 6, 77

Brice, D. K., 1973, Ion Implantation in Semiconductors and Other Materials, edited by Billy L. Crowder. (Plenum, New York, 1973), p. 171.

Brown, M. D., and C. D. Moak, 1972 , Phys. Rev. B 6, 90.

Brown, B. S., H. C. Freyhardt, and T. H. Blewitt 1974, J. Appl. Phys. 45, 2724.

Bullough, R., and R. S. Nelson, 1974, Physics in Technology, 5, 29.

Burton, J. J., 1971, Scr. Metall. 5, 449 . 
Cawthorne and Fulton, 1966

Cheshire and Poate, 1970

Dederichs, 1970

Dederichs, 1971

Development of Glass Electrical Insulator, 1973

EerNisse, 1971

EerNisse and Norris, 1974

Effects of Radiation on Substructure, 1973

Effects of Radiation on Structural Materials, 1974

Engle and Eatherly, 1972

Evans et al., 1972

Gissler, 1972

Goland, 1971

Harling et al ., 1975

Hersh, 1966

Hickman, 1972

Holmes-Siedle, 1974

Hopkins, 1974
Cawthorne, C., and E. J. Fulton, 1966 , Nature (Lond.) 216, 575.

Hughes and Henderson, 1972

Cheshire, I. M., and J. M. Poate, 1970, in Atomic Collision Phenomena in Solids, edited by D. W. Palmer, M. W. Thompson, and P. D. Townsend (North-Holland, Amsterdam, 1970), p. 351 .

Dederichs, P. H., 1970, Phys. Rev. B 1, 1306 .

Dederichs, P. H., 1971, Phys. Rev. B 4, 1041 .

"Development of Glass Electrical Insulator for Fusion Reactors," edited by T. G. Parker, Jr., Atomic International Division Report A1-73-45, 25 Oct. 1973 (unpublished).

EerNisse, E. P., 1971, in Ion Implantation in Semiconductors, edited by I. Ruge and J. Graul (Springer Verlag, Berlin, 1971), p. 17.

EerNisse, E. P., and C. B. Norris, 1974, J. Appl. Phys. 45, 5196.

"Effects of Radiation on Substructure and Mechanical Properties of Metals and Alloy," ASTM STP, 529, 1973.

"Proceedings of the Seventh International Symposium on Effects of Radiation on Structural Materials," Gatlinburg, Tenn., June 11-13, 1974, to be published.

Engle, G. B., and W. P. Eatherly, 1972, High Temperature-High Pressure 4, 119 .

Evans, J. H., R. Bullough, and A. M. Stoneham, 1972, in Radiation Induced Voids in Metals, edited by J. W. Corbett and L. C. Ianniello (U. S. A. E. C., CONF-710601, 1972), p. 522.

Gissler, W., 1972, Ber. Bunsenges. Phys. Chem., 76, 770 .

Goland, A. N., 1971, NATO Advanced Study Institute, Istanbul, Turkey, 1971, BNL Report 50336.

Harling, O. K., M. T. Thomas, R. L. Brodzinski, and L. A. Rancitelli, 1975, Phys. Rev. Lett. 34, 1340.

Hersh, H. N., 1966, Phys. Rev. 148, 928 .

Hickman, R. G., 1972, Technology of Controlled Thermonuclear Fusion Experiments and the Engineering Aspects of Fusion Reactors, Nov. 20-22, 1972, Austin, Tex., CONF-721111, p. 105.

Holmes-Siedle, A., 1974, Nature 251, 191.

Hopkins, G. R., 1974, in Proceedings 1st Topical Meeting on the Technology of Controlled Nuclear Fusion, April 16-19, 1974, San Diego, Calif., CONF-740402-P2, p. 437 .

Hughes, 1973

Ion Implantation, 1971

Ion Implantation, 1973

Ion Implantation, 1974 1969

Irradiation Produced Voids, 1975

Jenkins et al., 1975

Johnston et al ., 1973a

Johnston et al ., $1973 \mathrm{~b}$

Johnston et al ., 1974a

Johnston et al ., 1974b

Kaminsky et al., 1974

Katz and

Katz and

Key Issues, 1974
Hughes, A. E., and B. Henderson, 1972, in Point Defects in Solids, edited by J. H. Crawford, Jr., and L. M. Slifkin (Plenum, New York, 1972), Vol. 1, pp. $381-490$.

Irradiation Effects,

Johnson, H., 1969

Johnson, K., 1973

Wiedersich, 1971

Wiedersich, 1973
, 1973, Phys. Rev. Lett. 30, 1333.

Ion Implantation in Semiconductors, edited by I. Ruge and J. Graul (Springer Verlag, N. Y., 1971).

Ion Implantation in Semiconductors and Other Materials, edited by B. L. Crowder (Plenum Press, N. Y., 1973).

Ion Implantation in Semiconductors, Science and Technology, edited by S. Namba (Plenum Press, N. Y., 1974).

"Irradiation Effects in Structural Alloys for Thermal and Fast Reactors," ASTM Symposium San Francisco, 1968 (Special Technical Publication 457, ASTM, Philadelphia, 1969).

"The Physics of Irradiation Produced Voids," 1975, Proceedings of Consultants Conference on Void Formation, Harwell, England, September 9-11, 1974, edited by R. S. Nelson, A ERE Report R7934, 1975.

Jenkins, L. H., T. S. Noggle, R. E. Reed, M. J. Saltmarsh, and G. J. Smith, 1975, Appl. Phys. Lett. 26, 426.

Johnson, H. H., 1969, "Fundamental Aspects of Stress Corrosion Cracking," National Association Corrosion Eng., p. 439 .

Johnson, K. H., 1973, in Advances in Quantum Chemistry, edited by P. O. Löwdin (Academic Press, New York), Vol. 7, p. 143.

Johnston, W. G., J. H. Rosolowski, A. M. Turkalo, and T. Lauritzen, 1973, J. Nucl. Mater. 47, 155.

Johnston, W. G., J. H. Rosolowski, 1973, J. Nuc1. Mater. 48, 330.

Johnston, W. G., J. H. Rosolowski, A. M. Turkalo, and T. Lauritzen, 1974, J. Nucl. Mater., 54, 24.

Johnston, W. G., J. H. Ro solowski, A. M. Turkalo, and T. Lauritzen, 1974, General Electric Report No. 74, CRD291.

Kaminsky, M., J. H. Peavy, and S. K. Das, 1974, Phys. Rev. Lett. 32, 599.

Katz, J. L., and H. Wiedersich, 1971, J. Chem. Phys. 55, 1414

Katz, J. L., and H. Wiedersich, 1973, "Proceedings 1973, International Conference on Defects and Defect Clusters in BCC Metals and Their Alloys," Nucl. Met. 18, 530

"Key Issues Related to LMFBR DevelA. M. Turkalo, and T. Lauritzen, 
Kornelsen, 1972

Krakowski and Clinard, 1974

Krefft and A rnold, 1973

Kulcinski, 1974

Kulcinski, 1974

Kulcinski et al., 1975

Langley et al., 1974

Larson and Young, 1971

Lattice Defects in Semiconductors, 1974

Leibfried, 1965

Lindhard, Scharff, and Schi $\varnothing \mathrm{tt}, 1963$

LMFBR, 1972

Mansur et al ., 1973

Mansur et al., 1975

Materials

Performance, 1973 opment," 1974 Publication Hearings, National Science Foundation, Fission Energy Working Group, Chicago (August 14, 1974)

Kornelsen, E. V., 1972, Radiat. Eff. 13, 227.

Krakowski, R. A., and F. W. Clinard, Jr., 1974, Los Alamos Scientific Laboratory Report LA-UR-74-627, April, 1974

Krefft, G. B., and G. W. Arnold, 1973, in Ion Implantation in Semiconductors and Other Materials, edited by B. L. Crowder (Plenum Press, N. Y., 1973), p. 523.

Kulcinski, G. L., 1974, in Applications of Ion Beams to Solids, edited by S. T. Picraux, E. P. EerNisse and F. L.

Vook (Plenum Press, N. Y.), p. 613.

Kulcinski, G. L., 1974, “Radiation Damage by Neutrons to Materials in D-T Fusion Reactors," to be published in Proceedings of the IAEA Conference on Plasma Physics and Fusion Technology, Tokyo, November, 1974.

Kulcinski, G. L., P. G. Doran, and M. A. Abdou, June, 1975, to be published in Properties of Reactor Structural Alloys after Neutron on Particle Irradiation, STP-570, ASTM, 1975.

Langley, R. A., S. T. Picraux, and F. L. Vook, 1974, J. Nucl. Mater 53, 257.

Larson, B. C., and F. W. Young, Jr., 1971, Phys. Rev. B 4, 1709.

Proceedings of the 1974 International Conference on Lattice Defects in Semiconductors, Freiburg, July 22-25, 1974 (to be published).

Leibfried, G., 1965, Bestrahlungseffekte in Festkörpern (Teubner, Stuttgart, 1965).

Lindhard, J., M. Scharff, and H. E. Schiфtt, 1963, Kgl. Danske Videnskab. Selskab, Mat.-Fys. Medd. 33, no. 14.

LMFBR Program Plan: Fuels and Materials, AEC Report WASH-1107 (2nd ed), December 1972.

Mansur, L., P. Okamato, A. Taylor, and Che-Yu Li, 1973, "Proceedings 1973, International Conference on Defects and Defect Clusters in BCC Metals and Their Alloys," Nucl. Met. 18, 509 .

Mansur, L., P. Okamato, A. Taylor, and Che-Yu Li, 1975 to be published in Properties of Reactor Structural Alloys after Neutron or Particle Irradiation, STP-570, ASTM, 1975.

Symposium on Materials Performance in Operating Nuclear Systems, 1973 , edited by M. S. Wechsler and W. H. Smith, Ames, Iowa, 1973 (USA EC, CONF. TN 37830).
Meischner and Verbeek, 1974

Müller et al ., 1969

Müller et al ., 1970

Meischner, P., and H. Verbeek, 1974, J. Nucl., Mater. 53, 276.

Müller, E. W., S. B. McLane and J. A. Panitz, 1969, Surf. Sci. 17, 430.

Müller, E. W., S. V. Krishnaswamy, and S. B. McLane, 1970, Surf. Sci. 23, 112.

Nelson et al., 1970

Nelson, R. S., D. J. Mazey, and J. A Hudson, 1970, J. Nucl. Mater. 37, 1.

Norris, 1971

Norr is, D. I. R., 1971, "Voids Formed by Irradiation of Reactor Materials," Conference held on March 24-25, 1971, edited by S. F. Pugh, M. H. Loretto, and D. I. R. Norris, Reading, England, British Nuclear Energy Society.

Norris, 1972a

Norris, $1972 b$

Norris and

EerNisse, 1974

Northcliffe and Schilling, 1970

Nuckolls et al ., 1973

Okamota et al. 1974

Okamota and Wiedersich, 1974

Pabst and Palmer, 1974

Panitz, 1973

Panitz, 1974

Parkin and Schweitzer, 1974

Petroff and Seidman, 1973

Picraux and Vook, 1974

Point Defects, 1973

Point Defects, 1974

Pooley and Runciman, 1966

Primak, 1972

Pronko and Pronko, 1974

Radiation, 1971
Norris, D. I. R., 1972, Radiat. Eff., 14, 1 .

Norris, D. I. R., 1972b, Radiat. Eff., 15,1

Norris, C. B., and E. P. EerNisse, 1974, J. Appl. Phys. 45, 3876.

Northcliffe, L. C., and R. F. Schilling, 1970, Nucl. Data A 7, 223.

Nuckolls, J., J. Emmett, and F. Wood, 1973, Physics Today 26, (8), 46.

Okamota, P. R., A. T. Santhanam, H. Wiedersich, and A. Taylor, 1974, Nuclear Technology, 22, 45.

Okamota, P. R., and H. Wiedersich, 1974, J. Nucl. Mater., 53, 336.

Pabst, H. J., and D. W. Palmer, 1974, Radiat. Eff. 21, 135.

Panitz, J. A., 1973, Rev. Sci. Instrum. 44,1034

Panitz, J.A., 1974, J. Vac. Sci. Technol. 11, 206.

Parkin, D. M., and D. G. Schweitzer, 1974, Nuclear Tech. 22, 108.

Petroff, P., and D. N. Seidman, 1973, Acta Metall. 21, 323.

Picraux, S. T., and F. L. Vook, 1974 , in Applications of Ion Beams to Metals, edited by S. T. Picraux, E. P.

EerNisse, and F. L. Vook (Plenum Press, N. Y., 1974), p. 407.

"Point Defects and their Aggregates in Metals, 1973," Conference held at the University of Sussex, September 18-20, 1972, published in J. Phys. F. 3, no. 2, 233-496.

Point Defects in Solids, edited by J. H. Crawford, Jr. and L. Slifkin (Plenum, N. Y., 1974).

Pooley, D., and W. A. Runciman, 1966, Solid State Commun. 4, 351.

Primak, W., 1972, J. Appl. Phys. 43, 4927.

Pronko, P. P., and J. G. Pronko, 1974, Phys. Rev. B 9, 2870.

Radiation Induced Voids in Metals, 
Radiation Damage, 1973

Radiation Effects in Semiconductors, 1968

Radiation Effects in Semiconductors, 1971

Radiation Induced Voids, 1972

Reichelt et al., 1970

Robinson, 1972

Robinson and Thompson, 1974

Robinson and Torrens, 1974

RTPR, 1974

Russell, 1971

Scanlan et al., 1971

Seeger, 1973

Seidman, 1973

Sekula, 1971

Sidenius, 1974

Sigmund, 1969

Sigmund, 1972

Simmons and Balluffi, 1960

Snead et al., 1972

Sonder and Sibley, 1972 edited by J. W. Corbett, and L. C. Ianniello, June 9-11, 1971, Albany, N. Y., AEC Symposium Series (CONF-710601).

Radiation Damage and Defects in Semiconductors, edited by J. E. Whitehouse (The Institute of Physics, London, 1973).

Stickley et al., 1974

Radiation Effects in Semiconductors, edited by F. L. Vook (Plenum Press, N. Y., 1968).

Radiation Effects in Semiconductors, edited by J. W. Corbett and G. D. Watkins (Gordon and Breach, N. Y., 1971).

Radiation Induced Voids in Metals, 1972, edited by J. W. Corbett and L. C. Ianniello, AEC Symposium Series 26.

Reichelt, W. H., W. A. Ranken, C. V.

Weaver, A. W. Blackstock, A. J.

Patrick, and M. C. Chaney, 1970, Proceedings of Thermionic Conversion Specialist Conference, October, 1970, Miami Fla.

Robinson, M. T., 1972, in Radiation Induced Voids in Metals, edited by J. W. Corbett and L. C. Ianniello (U.S.A.E.C., CONF-710601), p. 397.

Robinson, J. E., and D. A. Thompson, 1974, Phys. Rev. Lett. 33, 1569.

Robinson, M. T., and I. M. Torrens, 1974, Phys. Rev. B 9, 5008.

An Engineering Design Study of a Reference Theta Pinch Reactor (RTPR) LA-5336, ANL-8019, Joint Report of the Los Alamos Scientific Laboratory and the Argonne National Laboratory (March, 1974).

Russell, K. C., 1971, Acta Metall. 19, 733.

Scanlan, R. M., D. L. Styris, and D. N. Seidman, 1971, Philos. Mag. 23, 1439.

Seeger, A., 1973, J. Phys. F. 3, 248.

Seidman, D. N., 1973, J. Phys. F. 3, 393.

Sekula, S. T., 1971, J. Appl. Phys. 42, 16.

Sidenius, G., 1974, Phys. Lett. 49A, 409 .

Sigmund, P., 1969, Phys. Rev. 184, 383.

Sigmund, P., 1972, Revue Roum. Phys. 17, 823, 969, 1079 .

Simmons, R. O., and R. W. Balluffi, 1960, Phys. Rev. 119, 600-5.

Snead, C. L., Jr., T. M. Hall, and A. N. Goland, 1972, Phys. Rev. Lett. 29,62 .

Sonder, E., and W. A. Sibley, 1972, in Point Defects in Solids, edited by J. H. Crawford, Jr., and L. M. Slifkin

(Plenum Press, N. Y.), Vol. 1, p. 201.
Sweedler et al., 1974

Switendick, 1972

Thompson, 1969

Tolk et al ., 197x

Ullmaier, 1973

Vernickel, 1974

Voids Formed by Irradiation, 1971

Völkl, 1972

Werner et al., 1972

Williams et al., 1974

Williams and Frank, 1974

Wilson, 1973

Stiegler, $1971 \quad$ Stiegler, J. O., 1971, in "Radiation Induced Voids in Metals," AEC Symposium, June 9-11, 1971, held in Albany, New York, edited by J. W. Corbett and L. C. Ianniello, AEC Symposium Series, CONF-710601.

Stickley, C. M., D. F. Albares, H. F. Taylor, and T. G. Giallorenzi, 1974, Topical Meeting on Integrated Optics (sponsored by Lasers and Electrooptics Technical Group, Optical Society of A merica), Jan. 21-24, 1974, Paper WB1 -1.

Stoneham, 1972 Stoneham, A. M., 1972, Ber. Bunsenges. Phys. Chem. 76, 816.

Sweedler, A. R., D. G. Schweitzer, and G. W. Webb, 1974, Phys. Rev. Lett. 33 168 .

Switendick, A. C., 1972, Ber. Bunsenges. Phys. Chem. 76, 535

Thompson, M. W., 1969, Defects and Radiation Damage in Metals (Cambridge University Press, 1969)

Tolk, N. H., W. van der Weg, and C. W. White, $197 \mathrm{x}$, private communication.

Ullmaier, H., 1973, in "Proceedings 1973, International Conference on Defects and Defect Clusters in BCC Metals and Their Alloys," Nucl. Met. 18, 363.

Vacancies and Interstitials in Metals, 1970, edited by A. Seeger, D. Schumacher, W. Schilling, and J. Diehl (North-Holland, Amsterdam, 1970).

Vernickel, H., 1974, Proceedings 1st Topical Conference on the Technology of Controlled Nuclear Fusion, April 16-18, 1974, San Diego, Calif. CONF-740402-P2, p. 347 .

"Voids Formed by Irradiation of Reactor Materials," Conference held on March 24-25, 1971, edited by S. F. Pugh, M. H. Loretto, and D. I. R. Norris, Reading, England, British Nuclear Energy Society.

Völkl, J., 1972, Ber. Bunsenges. Phys. Chem. 76, 797.

Werner, R. W., G. A. Carlson, J. Hovingh, J. D. Lee, and M. A. Peterson, 1972, Progress Report No. 1 on the Design Considerations for a Low Power Experimental Mirror Fusion Reactor, UCRL-74054.

Williams, J., T. Merson, F. Finch, F. Schilling, and T. Frank, in Proceedings of the First Topical Meeting on the Technology on Controlled Nuclear Fusion, edited by G. R. Hopkins, CONF-740402, April, 1974.

Williams, J. W., and T. G. Frank, 1974, Nucl. Technol. 22, 360.

Wilson, W. D., 1973, Radiat. Eff. $19,53$. 
Wilson and

Seidman, 1973
Wilson, K. L., and D. N. Seidman, 1973, in Proceedings 1973, Internation-

al Conference on Defects and Defect

Clusters in B. C. C. Metals and Their

Alloys, Nucl. Met. 18, p. 216.
Zebroski, 1974

Zebroski, E., 1974, American Physical Society Summer Study Conference, Brookhaven, June 17-27, 1974. 

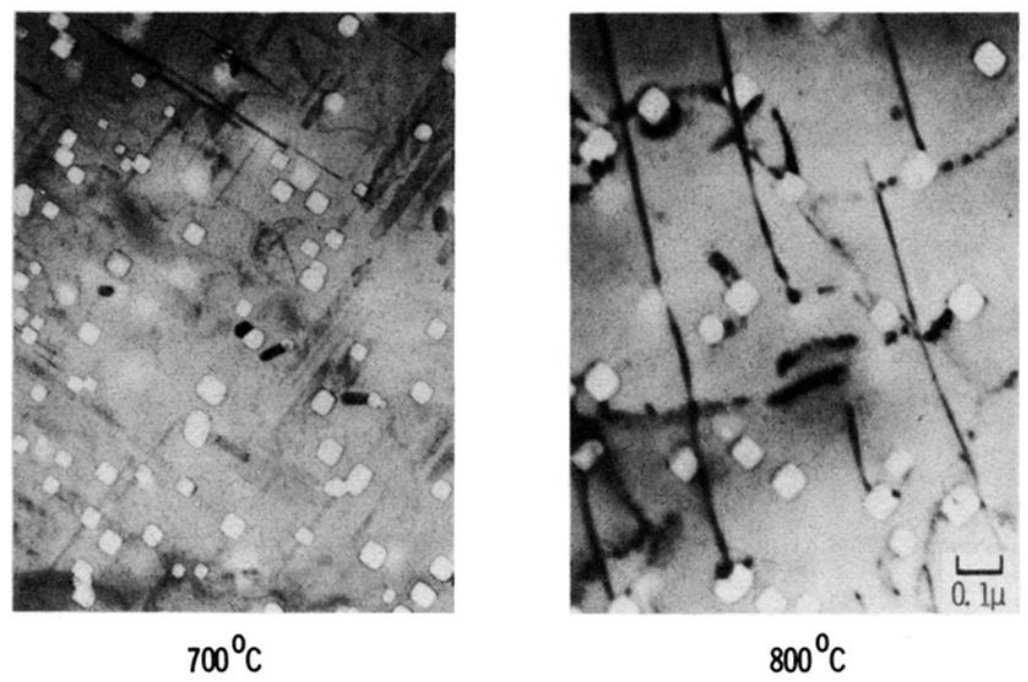

FIG. 2. Voids in vanadium after 7.5 MeV Ta bombardment to $\sim 30 \mathrm{dpa}$. 